\title{
Triple-pulse LIBS: Laser-induced breakdown spectroscopy signal enhancement by combination of pre-ablation and re-heating laser pulses
}

PROCHAZKA, D.; POŘÍZKA, P.; NOVOTNÝ, J.; HRDLIČKA, A.; NOVOTNÝ, K.; ŠPERKA, P.; KAISER, J.

Journal of Analytical Atomic Spectrometry

2020 , vol. 35 , iss. 2 , pp. 293-300

ISSN: $1364-5544$

DOI: https://doi.org/10.1039/C9JA00323A

Accepted manuscript

(C) The Royal Society of Chemistry, 2020 


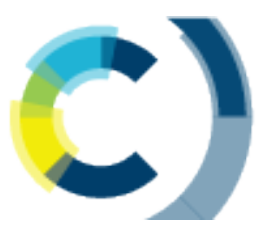

\section{JAAS}

\section{Triple-pulse LIBS: Laser-induced breakdown spectroscopy signal enhancement by combination of pre-ablation and re- heating laser pulses}

\begin{tabular}{|r|l|}
\hline Journal: & Journal of Analytical Atomic Spectrometry \\
\hline Manuscript ID & JA-ART-09-2019-000323 \\
\hline Article Type: & Paper \\
\hline Author: & 25 -Sep-2019 \\
\hline Complete List of Authors: & $\begin{array}{l}\text { Prochazka, David; Central European Institute of Technology Brno } \\
\text { University of Technology (CEITEC BUT), } \\
\text { Poř́zka, Pavel; Central European Institute of Technology Brno University } \\
\text { of Technology (CEITEC BUT) } \\
\text { Novotný, Jan; Central European Institute of Technology, } \\
\text { Hrdlička, Aleš; Masaryk University, CEITEC; Masaryk University, Faculty } \\
\text { of Science, Chemistry } \\
\text { Novotný, Karel; Masaryk University, Department of Chemistry } \\
\text { Šperka, Petr; Brno University of Technology } \\
\text { Kaiser, Jozef; Brno University of Technology, Institute of Physical } \\
\text { Engineering }\end{array}$ \\
\hline
\end{tabular}




\section{JAAS}

Journal of Analytical Atomic Spectrometry

\section{Guidelines for Referees}

Thank you very much for agreeing to review this manuscript for Journal of Analytical Atomic Spectrometry (JAAS)

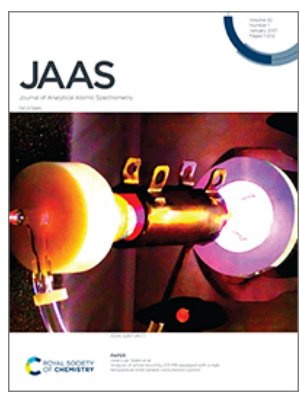
JAAS is the central journal for publishing innovative research on fundamentals, instrumentation, and methods in the determination, speciation and isotopic analysis of (trace) elements within all fields of application. This includes, but is not restricted to, the most recent progress, developments and achievements in all forms of atomic and elemental detection, isotope ratio determination, molecular analysis, plasma-based analysis and X-ray techniques.

JAAS' Impact Factor is 3.646 (2018 Journal Citation Reports ${ }^{\circledR}$ )

The following manuscript has been submitted for consideration as a

\section{FULL PAPER}

Full papers must represent a significant development in the particular field of analysis and are judged according to originality, quality of scientific content and contribution to existing knowledge. Although there is no page limit for Full papers, appropriateness of length to content of new science will be taken into consideration.

Please consider these standards when making your recommendation for publication in JAAS:

- Use the journal scope and expectations to assess the manuscript's suitability for publication in JAAS.

- Comment on the originality, importance, impact and reliability of the science. English language and grammatical errors do not need to be discussed in detail, except where it impedes scientific understanding.

- Note that routine or incremental work should not be recommended for publication.

- Check for an accompanying 'Significance to JAAS' statement

- Contact the Editorial Office if there is any conflict of interest, if the work has been previously published or if there is a significant part of the work which you are not able to referee with confidence.

Best regards,

\section{Professor Martin Resano}

Chair, JAAS

\section{Dr Jeanne Andres}

Executive Editor, JAAS

\section{Contact us}

Please visit our reviewer hub for further details of our processes, policies and reviewer responsibilities as well as guidance on how to review, or click the links below.
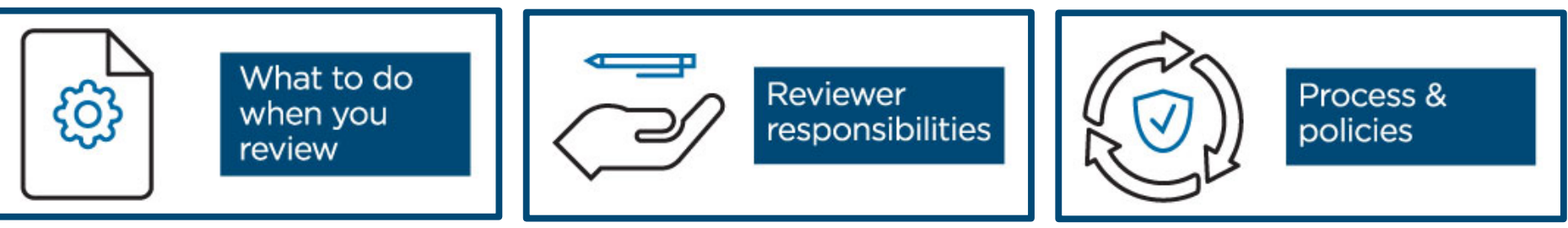


\section{Triple-pulse LIBS: Laser-induced breakdown spectroscopy signal enhancement by combination of pre-ablation and re-heating laser pulses}

Received 00th January 20xx, Accepted 00th January 20xx

DOI: $10.1039 / x 0 x \times 00000 x$

\author{
David Prochazka*a, b , Pavel Pořízka, ${ }^{a, d}$, Jan Novotnýa, b, d , Aleš Hrdličkac, Karel Novotnýc, Petr Šperka \\ b, Jozef Kaiser ${ }^{a, b, d}$
}

\section{Introduction}

Laser-Induced Breakdown Spectroscopy (LIBS) is a promising analytical tool based on atomic emission spectroscopy (OES). Detailed LIBS principles and instrumentation are described elsewhere ${ }^{1-4}$. Some of the LIBS advantages are the following: simultaneous multi-elemental analysis of samples in all states of matter, no need of sample preparation, short overall measurement time, the ability of stand-off measurements, fast chemical mapping, low cost of a single analysis, and fairly simple experimental setup. Thanks to the above-mentioned characteristics, LIBS has been recently used across scientific, industrial and forensic applications ${ }^{4-11}$. On the other hand, LIBS proves higher limits of detections (LOD), shot-to-shot variations 12 and sample matrix effects 13 in comparison to some competitive methods (e.g. X-ray fluorescence, inductively coupled plasma optical emission spectroscopy, spark-optical emission spectroscopy, flame atomic emission spectroscopy).

a. Materials Characterization and Advanced Coatings, Central European Institute of Technology, Purkyňova 656/123 Brno, Czech Republic; E-mail:

david.prochazka@ceitec.vutbr.cz

b. Faculty of Mechanical Engineering, Brno University of Technology, Technická 2 Brno, Czech Republic

Masaryk University, Faculty of Science, Department of Chemistry, Kamenice 735/5, 62500 Brno, Czech Republic

d. Lightigo s.r.o., Renneská tř́da 329/13, 63900 Brno, Czech Republic
There is a systematic effort of LIBS scientific community to increase the LIBS analytical performance. Some of the approached methods try to increase the emission intensity by external influences on plasma or ablation process. The external influence can be either 1) passive based on controlled environmental parameters, e.g. i) ambient pressures and/or atmosphere ${ }^{14}$, ii) transverse external magnetic field 15 , iii) plasma spatial confinement 16,17 , or 2 ) active, e.g. i) an ablation combined with fast electric discharge 18 or ii) microwave assisted LIBS ${ }^{19}$. Another approach of LIBS signal enhancement is the so called nanoparticle-enhanced LIBS (NELIBS) ${ }^{20}$, i.e. an application of metal nanoparticles on the sample surface. The above-mentioned approaches can be also combined as it was presented for example in $21,22$.

Probably one of the most frequently utilized approaches of LIBS emission signal enhancement is the so-called double-pulse LIBS (DP LIBS). The principle of DP LIBS lies in adding a secondary laser pulse to the conventional LIBS, which leads to a better coupling of the laser energy to the target and ablated material. More energy in the plasma plume leads to more efficient production of analyte atoms in excited state, which results in more intense optical emission signal 23,24 . Another advantage of DP LIBS configuration is a possibility to optimize the ablation and the plasma excitation separately. There are two basic geometrical configurations of DP LIBS - collinear and orthogonal. In the collinear arrangement both laser pulses 
share the geometrical path and are directed perpendicular to the sample surface. In the orthogonal configuration, the ablation laser pulse is perpendicular to the sample surface and the pre-ablation (or re-heating) laser pulse is delivered parallel to the sample surface, both pulses are perpendicular to each other. A more detailed description of DP LIBS geometrical configurations can be found in 4, 24, 25 .

The idea of DP LIBS is almost as old as the LIBS itself. The first paper dealing with two time resolved laser pulses was published by Piepmeier and Malmstadt in $1969{ }^{26}$ and subsequently by Scott and Strasheim in 1970 27. They found out that a large amount of energy of second laser pulse is absorbed by plasma plume which could lead to a further excitation of species in the plasma. However, the work by Cremers and Radziemski 28 from 1984 is considered as an initial study of DP LIBS. Since then, many papers studying the DP LIBS have been published ${ }^{23}$, 29-37. The authors studied the influence of laser pulse geometrical configuration $34,38-40$, wavelengths 41,42 , energies 35 , interpulse delays ${ }^{30}$ and durations ${ }^{42}$. It has also been shown that DP LIBS can suppress the matrix effect and fractionation ${ }^{29}$. In addition, the ability of orthogonal DP LIBS to achieve a high sensitivity simultaneously with a low sample damage can be utilized for a high resolution surface and the depth chemical mapping 43,44 . Several hypotheses were introduced based on these studies but the exact mechanism of the atomic and ionic emission signal enhancement is still not completely clear. Nevertheless, the conclusions of all the works are in good agreement: with emphasis to the orthogonal configuration, the dominant effect of pre-ablation DP LIBS lies in increasing the ablation rate, heating of the sample and reducing the atmospheric pressure and number density. The effect of the re-heating DP LIBS is mainly connected with the increase of the plasma temperature $24,25,40,45$. From the both mechanisms described above it can be assumed that the combination of pre-ablation and re-heating can work in synergy. It is also expected that the enhancement effect will be a function of excitation energy of the upper level of the spectral lines. For spectral lines with a low energy, upper level $(<5 \mathrm{eV})$ might stagnate or even decrease its intensity 24,45 . In several works, more than two pulses LIBS configurations were introduced ${ }^{31,46-49}$. Nevertheless, in all these works a collinear configuration was utilized. All the works concluded that utilization of three (or more) collinear, time resolved laser pulses increases the ablation rate in comparison to single pulse LIBS with the same total energy value. Based on this point of view, the enhanced ablation rate can be considered as an advantage - if the emission signal intensity is the primary interest, the collinear triple or multiple pulse LIBS can bring more intensive emission signal comparing to SP LIBS or even DP LIBS of the same total laser energy. On the other hand, if the main goal is a good spatial or depth resolution achieved by maintaining reasonable analytical performance, utilization of collinear multiple pulse LIBS is not the best choice.

The main objective of this work was to design a LIBS experimental configuration which allows achieving the highest possible analytical performance by simultaneous lowest possible sample damage. In other words, our goal was to keep the ablation rate low and to maintain the highest possible plasma emission signal at the same time. For this purpose, a combination of orthogonal pre-ablation and re-heating experimental configurations (in this work referred to as triplepulse LIBS and abbreviated as 3P LIBS) was utilized. To the best of our knowledge, 3P LIBS in orthogonal configuration had not been studied systematically before. In this work, the pre-pulse and re-heating DP LIBS experiments were optimized separately for the best signal to background ratio (SBR) and the optimal values were compared with optimized intensity of 3P LIBS experiment. The ablated volume for each experimental configuration (SP LIBS, pre-ablation DP LIBS, re-heating DP LIBS and $3 \mathrm{P}$ LIBS) was estimated by using a $3 \mathrm{D}$ optical microscope and the plasma temperature for each configuration was determined from the slope of Boltzmann plot. In addition, with the emphasis to the sample damage, the ablated mass and the dimensions of ablation craters for 3P LIBS and SP LIBS with the same emission signal were compared.

\section{Experimental}

\section{Triple-Pulse LIBS setup}

LIBS measurements were performed using the table top LIBS setup. The setup was composed of an instrumental compartment and an interaction chamber ${ }^{50}$ (nr. 5 in Fig. 1). $\mathrm{Nd}$ :YAG laser Brilliant b (Quantel, FR, $532 \mathrm{~nm}, 10 \mathrm{~Hz}$, pulse width $\sim 10 \mathrm{~ns}, \mathrm{nr} .2$ in Fig. 1) was used as the ablation laser source. The laser beam intensity was controlled with optical attenuator (Eksma optics, LT) and focused on the sample surface with plano-kovex lens (Thorlabs, DE) with a focal length of $75 \mathrm{~mm}$. Nd:YAG laser LQ529 (SOLAR, BE, $532 \mathrm{~nm}, 10 \mathrm{~Hz}$, pulse width $12 \mathrm{~ns}, \mathrm{nr} .1$ in Fig. 1) was used for the pre-ablation. The diode pumped solid state Nd:YAG laser DF251 (SOL Instruments, BE, $1064 \mathrm{~nm}, 10 \mathrm{~Hz}$, pulse width 14 ns, nr. 3 in Fig. 1) was employed for the third laser pulse (plasma reheating). The wavelength of the re-heating laser was selected with regards to the work ${ }^{41}$ where the authors concluded that IR re-heating laser pulse would always cause some enhancement regardless of conditions. The pre-ablation and reheating laser pulses were directed perpendicular to the ablation laser and to each other and parallel to the sample surface. Both pulses were focused slightly above the sample surface using two
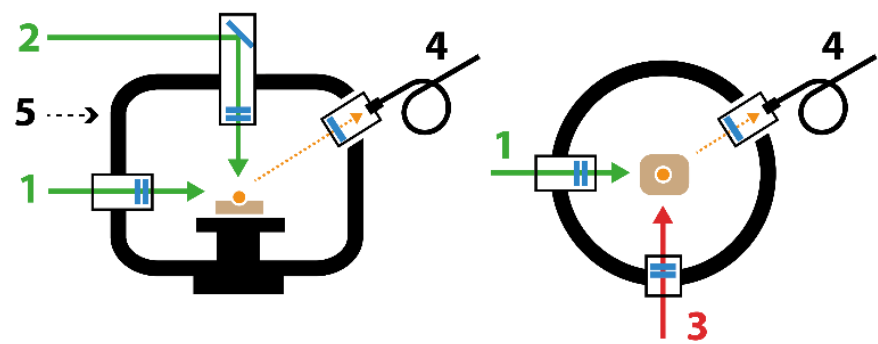

Figure 1 Front view (left) and top view (right) schematic picture of the interaction chamber with laser pulses and collection optics. All laser pulses are perpendicular to each other. Ablation pulse (2) is directed from the top of the chamber (5), perpendicular to the sample surface, pre-ablation pulse (1) came from the left side of the chamber (5) collinear to the sample surface and re-heating pulse (3) is directed from the front of the chamber (5) collinear to the sample surface. The collection optics (4) is placed on the right side of the chamber. 
planoconvex lenses with a focal length of $50 \mathrm{~mm}$ (Thorlabs, DE). The ablation laser pulse was led into the interaction chamber from the top (nr. 2 in Fig. 1) and the other laser pulses from the front of the chamber (nr. 3 in Fig. 1) and the left side of the chamber (nr. 1 in Fig. 1) respectively. The re-heating pulse was focused $1 \mathrm{~mm}$ behind the plasma plume. The time-resolved measurement was performed with two lab made computer controlled digital delay generators (jitter $<40 \mathrm{~ns}$ ).

Plasma radiation was collected using mirror collection optics (CC52, Andor, UK) (nr. 4 in Fig. 1) and led via the optical cable (50 $\mu \mathrm{m}$ core diameter) on the entrance of echelle spectrometer (Mechele 5000, Andor, UK). The radiation was recorded on the iCCD camera (iStar 734i, Andor, UK). The setup provided a resolution power $(\lambda / \Delta \lambda)$ of 5000 . The relative efficiency of the setup was calibrated using the deutherium-halogen lamp (Ocean Optics, FL).

The laser pulse energies, gate delay and gate width were kept constant throughout all experiments and their values were as follows: pre-ablation laser pulse $~ 100 \mathrm{~mJ} /$ pulse; ablation laser pulse $\sim 10 \mathrm{~mJ} /$ pulse; re-heating laser pulse $\sim 80 \mathrm{~mJ} /$ pulse; gate delay $=1.5 \mu$ s (measured always from the last laser pulse); gate width $=15 \mu \mathrm{s}$.

The LIBS craters dimensions and volume were measured with a 3D optical microscope Contour GT-X (Bruker, DE) and analyzed with software Vision64 (Bruker, DE).

\section{Data Processing}

Generally, the spectral line emission signal refers to any point on the selected spectral range which correlates with its area. Background is a mean value from the region in proximity of the selected spectral line (without any interfering spectral line). In this work, the signal describes maximum of the spectral line intensity above the background. Enhancement is described by a ratio of the selected spectral line intensity of given configuration to the intensity of the respective spectral line in SP LIBS configuration.

The data were treated as follows: First of all, a continuum background was subtracted from each spectra by moving minimum algorithm ${ }^{51}$. Then, the signal to background ratio (or enhancement) was calculated for each spectrum and also the mean value and standard deviation were calculated for the corresponding experiment. All computations and data operations were performed in $\mathrm{R}$ project ${ }^{52}$.

\section{Sample}

A low alloyed, high homogeneous steel sample BAM SUS-1 R was utilized for all measurements. This sample was selected for two reasons: i) because of its high homogeneity which prevents fluctuations and misinterpretations of data; ii) because the iron spectral lines are well described and offers a high amount of diverse values of upper level energies. Moreover, steel samples were often utilized in literature dealing with DP LIBS enhancement so the conclusions can be compared on matrix matched samples.

\section{Results and discussion}

\section{Optimization}

The energy of ablation laser pulse was selected with an emphasis on the low sample damage, however, while maintaining a reasonable sensitivity. Specifically, for SP LIBS configuration, we changed the laser pulse energy from higher values to lower and inspected the spectra for trace elements spectral lines (Cu I 324.75 nm, Mn I 403.08 nm, Cr I 425.43 nm and $\mathrm{Ni}$ I $341.47 \mathrm{~nm}$ ). The utilized laser pulse energy was the lowest with all these spectral lines intensities above the limit of detections (LOD) ${ }^{53}$. This ablation laser pulse energy was then kept constant for both DP LIBS experiments and for the 3P LIBS experiment. We realized that the proposed 3P LIBS experiment could possibly work even with a lower ablation laser pulse energy, but in order to quantify the enhancement for the same ablation laser pulse energy, a detectable signal was necessary also for SP LIBS. In other words, we tried to prevent calculating the enhancement from nearly zero SP LIBS signal. Moreover, by optimization of gate delay for each configuration separately and laser pulses energies (pre-ablation and reheating) could be possibly better results achieved, but this is out of scope of this article.

In order to obtain the best possible performance for both preablation and re-heating DP LIBS, the interpulse delays were optimized. The interpulse delays for pre-ablation DP LIBS were changed from $-50 \mu \mathrm{s}$ to $0 \mu \mathrm{s}$ with a step of $1 \mu \mathrm{s}$ and for reheating from $0 \mu$ s to $20 \mu$ s with the same step. For each specific setup, 25 measurements were performed in the same spot in order to achieve statistically significant results. To quantify the dependence of DP LIBS signal on the time between the pulses,
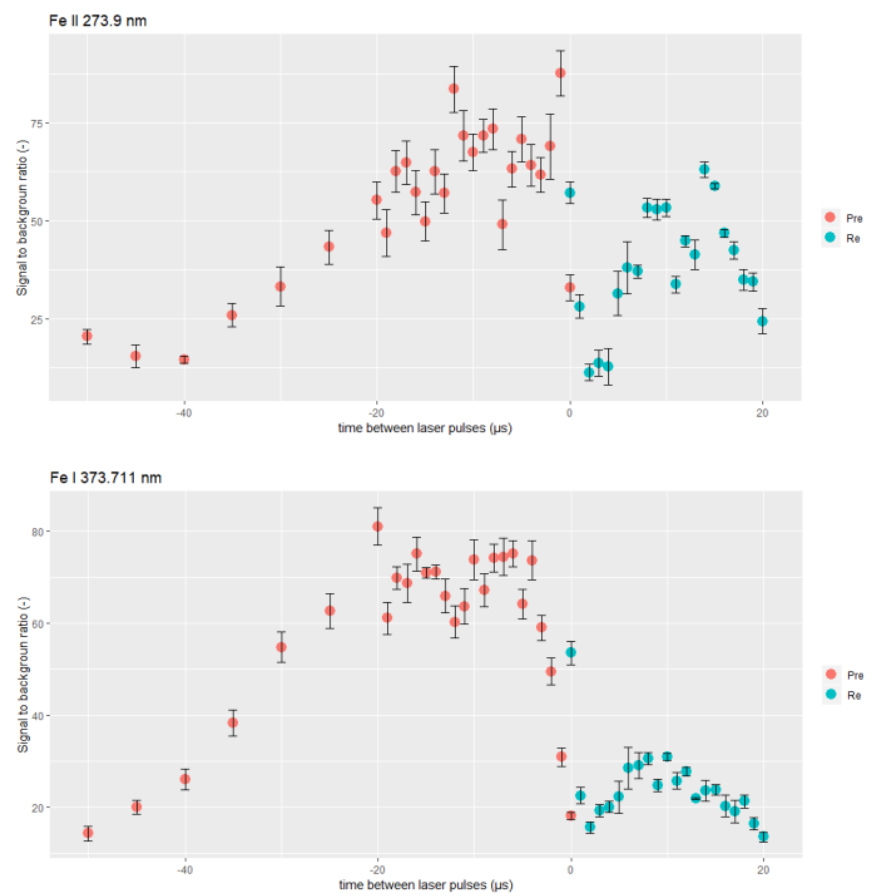

Figure 2 Signal to background ratio (SBR) as a function of delay between the ablation and pre-ablation and re-heating pulse respectively (red points are for pre-ablation and blue points for re-heating). 

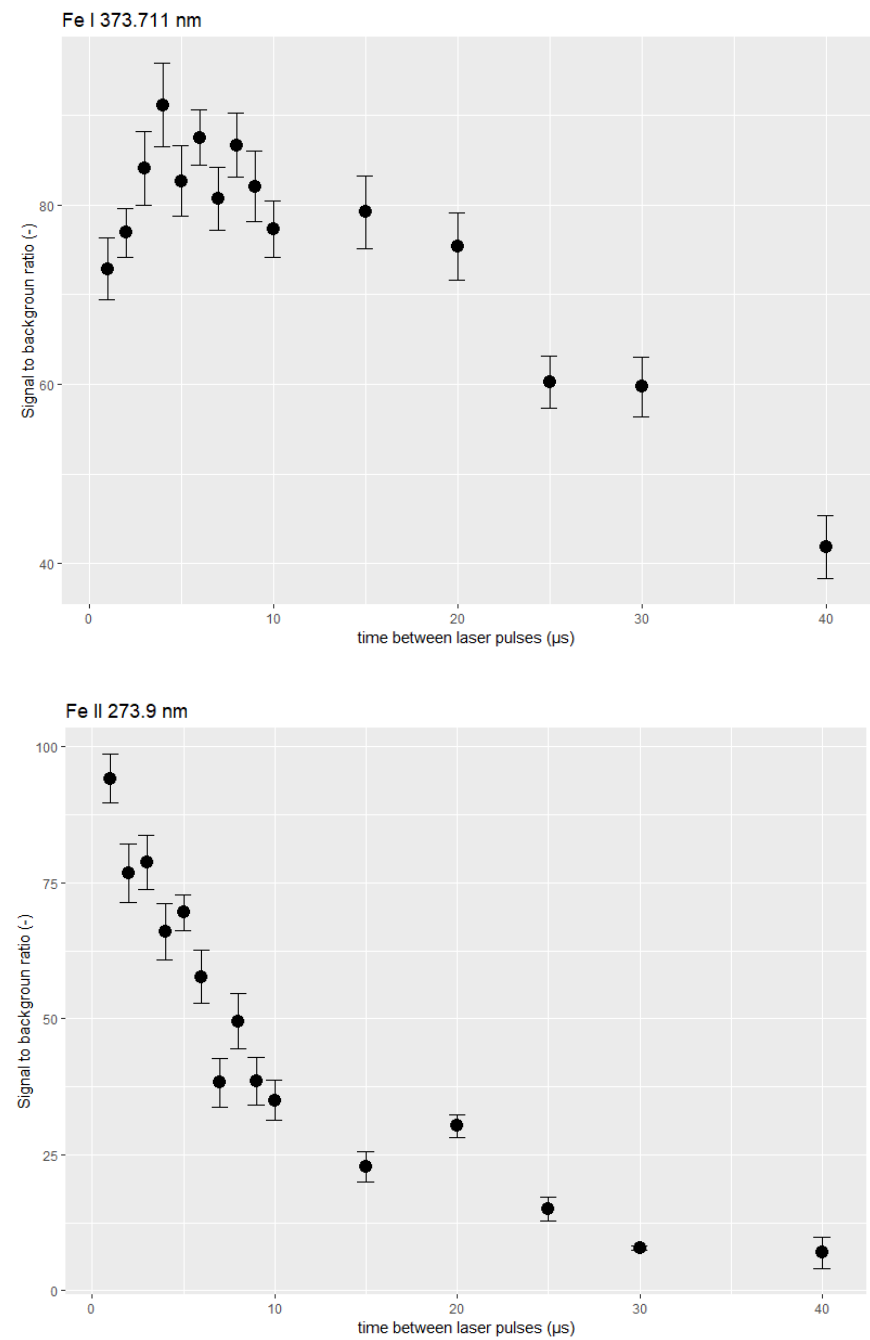

Figure 3 Signal to background ratio (SBR) as a function of delay after the ablation laser pulse. The pre-ablation pulse was constantly $8 \mu$ s before the ablation pulse.

the signal to background ratio (SBR) of ionic (Fe II $273.711 \mathrm{~nm}$ ) and atomic ( $\mathrm{Fe}$ I $373.711 \mathrm{~nm}$ ) spectral lines of iron were calculated (see graphs in the Fig. 2). The optimal range of time between the laser pulses for both pre-ablation and re-heating can be estimated based on the graphs. As there is no sharp peak in the graphs in Fig. 2 and the data proves a low stability, we selected a time range where most of SBR values is above 65 (pre-ablation) and 50 (re-heating) for Fe II and 70 (pre-ablation) and 25 (re-heating) for Fe I (see Tab. 1).

The optimization of the re-heating pulse in 3P LIBS configuration was performed analogously. Based on the results of DP LIBS optimization, the time of $8 \mu \mathrm{s}$ was chosen and kept constant for the pre-ablation laser pulse. The interpulse delay (between ablation and re-heating pulses) was optimized for maximal SBR in the range from $1 \mu \mathrm{s}$ to $40 \mu \mathrm{s}$ (see Fig. 3). It is obvious from the graphs that the optimal time for the atomic line is $4 \mu \mathrm{s}$ after ablation and for the ionic line $1 \mu$ s after ablation. The lower SBR Table 1 Range of optimal delay times for pre-ablation DP LIBS, re-heating DP LIBS and $3 P$ LIBS (pre-ablation + reheating). The pre-ablation delay time for 3P LIBS was $-8 \mu \mathrm{s}$.

\begin{tabular}{llll}
\hline Line & $\begin{array}{l}\text { Pre-ablation } \\
\text { delay }(\mu \mathrm{s})\end{array}$ & $\begin{array}{l}\text { Re-heating } \\
\text { delay }(\mu \mathrm{s})\end{array}$ & $\begin{array}{l}\text { 3P } \\
\text { ( } \mu \mathrm{s})\end{array}$ \\
\hline Fe I $373.711 \mathrm{~nm}$ & -20 to -4 & 7 to 12 & 4 \\
Fe II $273.9 \mathrm{~nm}$ & -12 to -1 & 8 to 15 & 1
\end{tabular}

and emission signal stability of the re-heating DP LIBS with respect to pre-ablation DP LIBS could be caused by a low energy of ablation laser pulse and resulting in a small size of ablation plasma plume. For such conditions, even small position fluctuations, either of plasma or re-heating laser pulse, can cause a change of the portion of re-heating laser pulse energy absorbed by the plasma. On the other hand, the position and the volume of the pre-ablation air spark were stable so that they always interacted with the ablation plasma plume in the same way. For the 3P LIBS, the plasma volume and stability were increased by the pre-ablation and this problem was negligible. It is noteworthy that optimal times between laser pulses for reheating DP LIBS and 3P LIBS differ. Based on the study conducted in 40 it could be caused by a faster plasma expansion in the rarefied gas region caused by a shockwave of the preablation plasma plume. Together with the fact that main mechanism of infrared laser absorption is inverse Bremsstrahlung, it is clear that a higher plasma density and shorter times between laser pulses respectively were necessary.

\section{Signal enhancement}

Iron, as a matrix element, and four trace elements typical for steel $(\mathrm{Cu}, \mathrm{Ni}, \mathrm{Cr}$ and $\mathrm{Mn})$ were selected for the study of signal enhancement. Fig. 4 depicts spectral regions with labeled spectral lines for average spectra (all 25 measurements) for all experimental configurations (SP, both DPs, 3P) in optimal conditions. SP LIBS intensity is depicted in right $\mathrm{Y}$-axis and the DP LIBS and 3P LIBS intensity are on the left side $Y$-axis. The double-Y graph was selected to show that the spectral lines are well distinguishable and have a reasonable intensity even in case of the SP LIBS experiment. A significant increase in spectral emission intensity can be observed in all regions for both DP LIBS and 3P LIBS with respect to single laser pulse operation. By closer look it can be seen that the strongest 3P LIBS enhancement was recorded in case of ionic line Fe II $273.9 \mathrm{~nm}$. In Fig. 5 we can see the enhancement of selected spectral lines as a function of upper level energy. The selected spectral lines enhancement for each configuration and the values of excitation energy are listed in Tab. 2 (a complete list of utilized spectral lines and respective excitation energies can be found in supplementary material). The graph in Fig. 5 shows clearly that the spectral lines with higher excitation energy prove a higher enhancement. This conclusion is in good agreement with the works dealing with orthogonal DP LIBS ${ }^{34,35}$. Moreover, it can be seen that the slope of linear fit is almost the same for preablation $\left(18.39 \mathrm{eV}^{-1}\right)$ and $3 P$ LIBS $\left(19.27 \mathrm{eV}^{-1}\right)$, but lower for the re-heating $\left(11.5 \mathrm{eV}^{-1}\right)$. It was expected that the increased ablation rate would result in the overall emission signal enhancement for pre-ablation DP LIBS and 3P LIBS respectively. On the other hand, DP LIBS was expected to shift the ratio of neutral and ionic species toward to the ionic ones as a consequence of re-heating. This effect should lead to a higher slope of re-heating DP LIBS in comparison to both pre-ablation DP LIBS and 3P LIBS. Nevertheless, the slopes of the linear fit differs from the expectations. The possible explanation could be that the plasma temperature increase is insufficient for a 

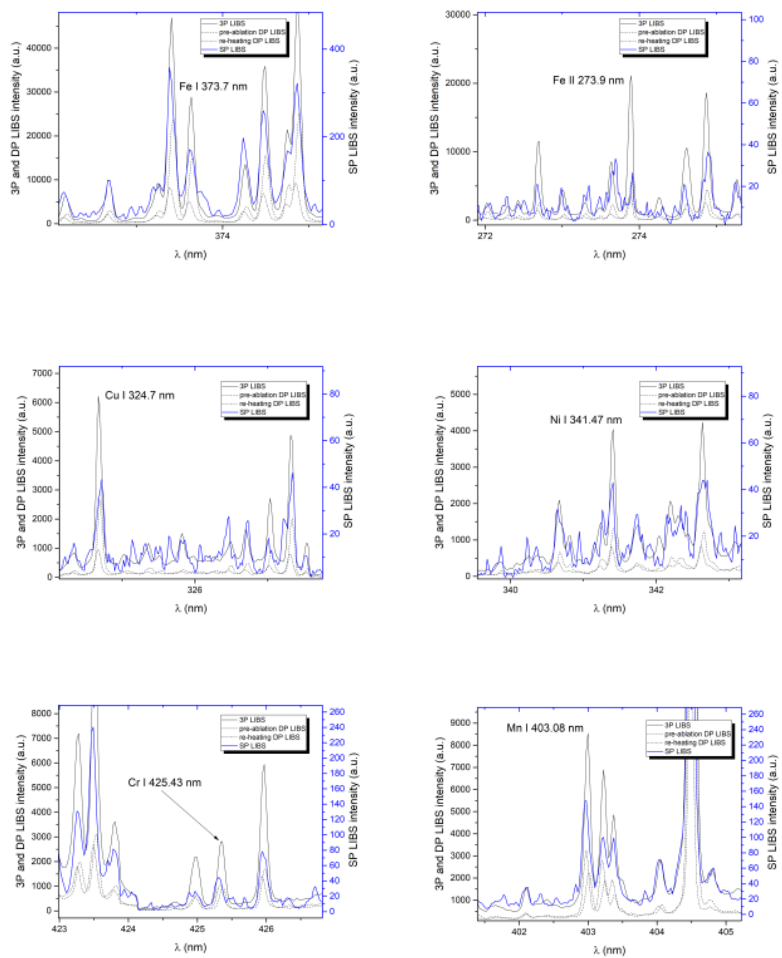

Figure 4 Selected parts of emission spectra of 3P LIBS (solid black line) pre-ablation DP LIBS (dashed line) re-heating DP LIBS (dash dot line) and SP LIBS (solid blue line). Intensity of DP LIBS and 3P LIBS is on the left axis and intensity of SP LIBS is on the right axis of graphs.

significant increase in plasma ionization. However, we did not study this effect in more detail.

\section{Plasma temperature}

For the optimal conditions of each experimental configuration, plasma temperature was calculated utilizing the slope of Boltzmann plot (see supplementary materials). The higher error is probably caused by a long gate width and the dynamic change

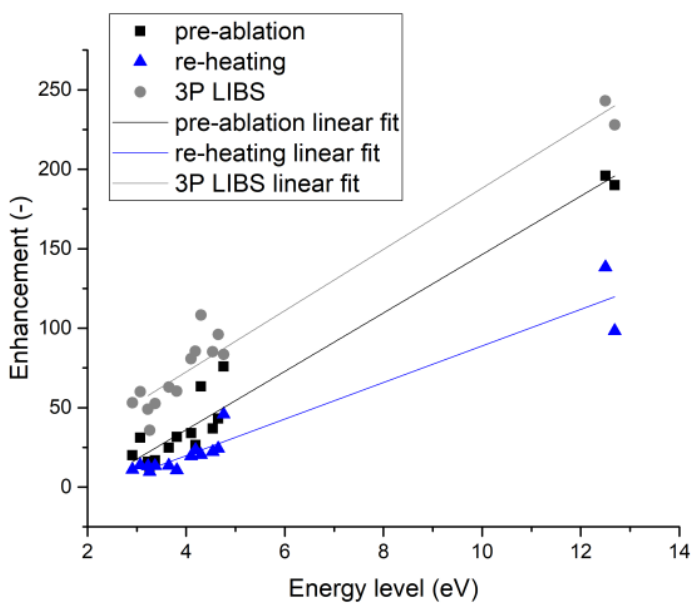

Figure 5 Enhancement of selected spectral lines as a function of upper-level energy for pre-ablation (squares), re-heating (triangles) and 3P LIBS (circles). The errors are listed in Tab. 2.
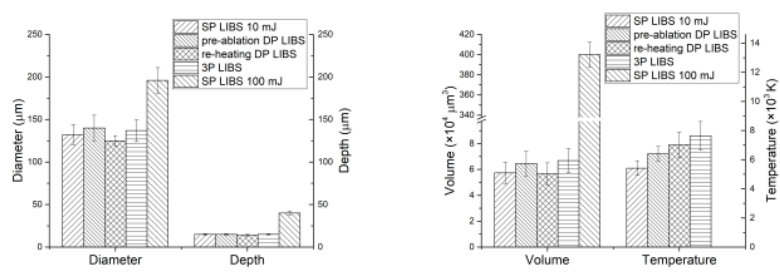

Figure 6 Graphs of diameter, depth and volume of ablation craters for each experimental configuration under study. In the graph on right axis the respective temperature for selected experimental configuration is depicted. The temperature for SP LIBS experiment with $100 \mathrm{~mJ}$ ablation energy was not determined.

of plasma temperature during this time. The calculations and a list of utilized spectral lines are given in supplementary materials. In accordance with our expectations, the SP LIBS experiment shows the lowest temperature. Both DP LIBS configurations have a similar plasma temperature - the small difference can be explained by ablated mass, where the preablation is expected to have a higher ablation rate. The highest temperature in 3P LIBS can be explained by higher plasma dimensions in comparison to re-heating DP LIBS which results in more effective laser pulse - plasma coupling.

\section{Crater volume}

The ablation crater dimensions and crater volume were determined for five experimental configurations - SP LIBS with laser pulse energy of $10 \mathrm{~mJ}$ and $100 \mathrm{~mJ}$, both above described DP LIBS and 3P LIBS measurements. For each configuration, 5 ablation craters were created. Each ablation crater was created by 25 consecutive shots in the same spot. The $100 \mathrm{~mJ}$ experiment proves that the emission signal of the trace elements listed above is comparable to the 3P LIBS. Also the crater diameters are comparable (137 $\mu \mathrm{m}$ for 3P LIBS vs $196 \mu \mathrm{m}$ for SP LIBS) but the depth is 2 times larger in case of the SP LIBS and the volume is two orders of magnitude (see Fig. 6) larger. In supplementary material, there is presented the following: the ablation crater pictures and respective profiles along $x$-axes of $100 \mathrm{~mJ}$ SP LIBS and 3P LIBS as well as the exact numbers of craters dimensions, volume and respective plasma temperature for each experimental configuration.

Table 2 Signal enhancement as a ratio of both DP LIBS configurations and 3P LIBS spectral line intensity to corresponding spectral line intensity of SP LIBS. Complete list of utilized spectral lines is listed in supplementary material.

\begin{tabular}{ccccc}
\hline \multirow{2}{*}{$\begin{array}{c}\text { Wavelength } \\
\text { (nm) }\end{array}$} & $\begin{array}{c}\text { Signal enhancement (-) } \\
\text { Pblation }\end{array}$ & $\begin{array}{c}\text { Re- } \\
\text { heating }\end{array}$ & 3P LIBS & $\begin{array}{c}\text { Upper } \\
\text { level } \\
\text { energy } \\
\text { (eV) }\end{array}$ \\
\hline Fe I 367.99 & $14 \pm 2$ & $11 \pm 4$ & $44 \pm 6$ & 3.37 \\
Fe I 373.71 & $63 \pm 2$ & $21 \pm 5$ & $108 \pm 7$ & 4.3 \\
Fe I 382.78 & $34 \pm 3$ & $19 \pm 3$ & $80 \pm 11$ & 4.10 \\
Fe I 404.58 & $43 \pm 3$ & $24 \pm 5$ & $85 \pm 9$ & 4.65 \\
Fe II 261.38 & $190 \pm 8$ & $98 \pm 6$ & $228 \pm 12$ & 12.69 \\
Mn I 403.08 & $31 \pm 2$ & $14 \pm 5$ & $60 \pm 7$ & 3.07 \\
Cr I 425.43 & $20 \pm 3$ & $11 \pm 5$ & $53 \pm 7$ & 2.91 \\
Cu I 324.75 & $28 \pm 3$ & $25 \pm 4$ & $74 \pm 6$ & 3.81 \\
Ni I 341.476 & $25 \pm 2$ & $14 \pm 5$ & $63 \pm 8$ & 3.65
\end{tabular}




\section{Conclusions}

The main objective of this work was to propose a LIBS experimental configuration which enables to achieve the highest possible analytical performance and the lowest possible sample damage at the same time. A combination of preablation and re-heating laser pulses was used for this purpose. The interpulse delays for pre-ablation and re-heating DP LIBS and afterwards also for 3P LIBS were optimized. Based on the presented data, it can be concluded that the highest enhancement was achieved by 3P LIBS, lower enhancement was observed by pre-ablation DP LIBS and the lowest enhancement proved re-heating DP LIBS. It is also evident that spectral lines with higher upper level energy prove a higher enhancement. In order to understand the process, the ablation craters dimaeters were measured and the plasma temperatures were determined for each configuration. We noticed that pre-ablation laser pulse had enhanced the ablation rate and also the temperature. A comparable temperature increase was noticed also by reheating pulse, however the ablation crater dimensions were aproximately the same as for SP LIBS. The highest ablation rate and temperature were noticed by $3 \mathrm{P}$ LIBS, which agrees with the higher signal enhancement effect. This study can be accomplished by the piece of knowledge that the most recommendable configuration is $3 \mathrm{P}$ LIBS showing a tremendous two-orders of magnitude amplification effect.

\section{Conflicts of interest}

There are no conflicts to declare.

\section{Acknowledgements}

This research was carried out under the project CEITEC 2020 (LQ1601) with financial support from the Ministry of Education, Youth and Sports of the Czech Republic under the National Sustainability Programme II, CEITEC Nano Research Infrastructure (MEYS CR, 2016-2019) and Ceitec Nano+ project ID CZ.02.1.01/0.0/0.0/16_013/0001728 under the program OP RDE. A.H. and K.N. acknowledge the support of the Grant Agency of Masaryk University under the project MUNI/A/1375/2018. J.K. acknowledges the support of the Brno University of Technology through grant FSI-S-17-4506.

\section{Supplementary material}

Boltzmann plot

For the purposes of laser induced plasma temperature determination the well-known Boltzmann equation can be rewritten in the following form:

$\ln \frac{{ }^{q} I_{i j}^{S}}{g_{i}^{S} A_{i j}^{S}}=\frac{-E_{i}^{S}}{k_{B} T}+\ln \frac{n^{S}}{{ }^{q} U^{S}(T)}$,

where ${ }^{q} I_{i j}^{S}$ (photons $\mathrm{cm}^{-3} \mathrm{~s}^{-1}$ ) is the intensity of atomic or ionic line of element $S, q$ is the ionization stage, $i, j$ are the indexes of the higher and lower energetic quantum states of the same ionization stage $q, n^{S}\left(\mathrm{~cm}^{-3}\right)$ is the total number density of species $S, A_{i j}^{S}\left(\mathrm{~s}^{-1}\right)$ is the transition probability of upper level of species $S, g_{i}^{S}$ (dimensionless) is the statistical weight of upper level, $E_{i}^{S}(\mathrm{eV})$ is the excitation energy of upper level, $T(\mathrm{~K})$ is the temperature, $k_{B}\left(\mathrm{eVK}^{-1}\right)$ is the Boltzmann constant and ${ }^{q} U^{S}(T)$ (dimensionless) is internal partition function of selected species at temperature $T(\mathrm{~K})$ :

${ }^{q} U^{S}(T)=\sum_{i} g_{i} e^{-E_{i}^{S} / k_{B} T}$

If the left side of the equation (1) is represented as a function of energy of the upper level for different transitions the result should leads to a linear plot. The plasma temperature may be then obtained from the slope of the plot.

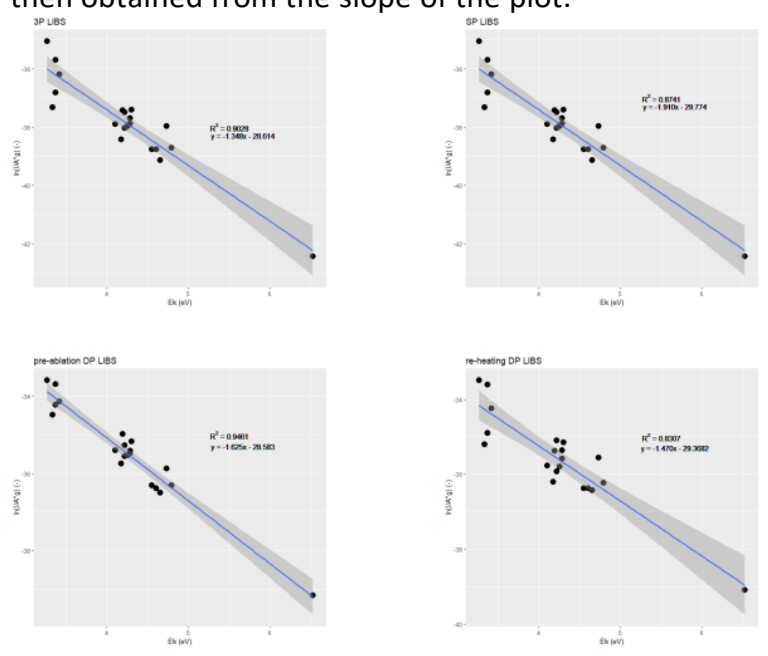

Figure S1 Examples of Boltzmann plot in the SP LIBS, DP LIBS (pre-ablation and reheating) and $3 \mathrm{P}$ LIBS.

Table S1 List of Fe I spectral lines utilized for Boltzmann plot

\begin{tabular}{cll}
\hline Central_wavelength & Ek (eV) & Ak* $\left.^{*} \mathbf{~ s}^{-1}\right)$ \\
\hline 367.9913 & 3.37 & 12400000 \\
368.7456 & 4.22036 & 72000000 \\
371.9934 & 3.332 & 178000000 \\
372.2563 & 3.4169 & 24800000 \\
372.7618 & 4.2833 & 112000000 \\
373.4863 & 4.1777 & 991000000 \\
373.7131 & 3.3683 & 127000000 \\
374.3361 & 4.3013 & 78000000 \\
374.9485 & 4.2204 & 687000000 \\
375.8232 & 4.2562 & 444000000 \\
376.3788 & 4.2833 & 272000000 \\
376.5538 & 6.5283 & 1430000000 \\
375.8232 & 4.2562 & 444000000 \\
382.0425 & 4.1034 & 600000000 \\
382.7822 & 4.7955 & 525000000 \\
387.2501 & 4.1909 & 52500000 \\
389.9707 & 3.2657 & 12900000
\end{tabular}




$\begin{array}{lll}390.2945 & 4.7331 & 150000000 \\ 400.5242 & 4.652 & 102000000 \\ 404.5812 & 4.5485 & 776000000 \\ 406.3594 & 4.6076 & 466000000\end{array}$

Signal enhancement

Table S2 Signal enhancement as a ratio of both DP LIBS configurations and 3P LIBS spectral line intensity to corresponding spectral line intensity of SP LIBS.

\begin{tabular}{|c|c|c|c|c|}
\hline \multirow[b]{2}{*}{$\begin{array}{l}\text { Wavelength } \\
(\mathrm{nm})\end{array}$} & \multicolumn{3}{|c|}{ Signal enhancement (-) } & \multirow{2}{*}{$\begin{array}{l}\text { Upper } \\
\text { level } \\
\text { energy } \\
\text { (eV) }\end{array}$} \\
\hline & $\begin{array}{l}\text { Pre- } \\
\text { ablation }\end{array}$ & $\begin{array}{l}\text { Re- } \\
\text { heating }\end{array}$ & 3P LIBS & \\
\hline Fe I 367.99 & $14 \pm 2$ & $11 \pm 4$ & $44 \pm 6$ & 3.37 \\
\hline Fe I 368.75 & $17 \pm 3$ & $13 \pm 6$ & $53 \pm 8$ & 4.22 \\
\hline Fe I 372.25 & $22 \pm 2$ & $14 \pm 6$ & $55 \pm 8$ & 3.41 \\
\hline Fe I 372.76 & $23 \pm 2$ & $17 \pm 5$ & $67 \pm 6$ & 4.28 \\
\hline Fe I 373.71 & $63 \pm 2$ & $21 \pm 5$ & $108 \pm 7$ & 4.3 \\
\hline Fe I 382.78 & $34 \pm 3$ & $19 \pm 3$ & $80 \pm 11$ & 4.10 \\
\hline Fe I 387.25 & $11 \pm 5$ & $10 \pm 2$ & $36 \pm 5$ & 3.26 \\
\hline Fe I 389.97 & $27 \pm 2$ & $23 \pm 6$ & $86 \pm 7$ & 4.19 \\
\hline Fe I 390.29 & $15 \pm 3$ & $13 \pm 3$ & $49 \pm 6$ & 3.22 \\
\hline Fe I 404.58 & $43 \pm 3$ & $24 \pm 5$ & $85 \pm 9$ & 4.65 \\
\hline Fe I 406.36 & $36 \pm 3$ & $22 \pm 5$ & $85 \pm 10$ & 4.54 \\
\hline Fe II 259.94 & $196 \pm 7$ & $138 \pm 7$ & $243 \pm 15$ & 12.5 \\
\hline Fe II 261.38 & $190 \pm 8$ & $98 \pm 6$ & $228 \pm 12$ & 12.69 \\
\hline Mn I 403.08 & $31 \pm 2$ & $14 \pm 5$ & $60 \pm 7$ & 3.07 \\
\hline Cr I 425.43 & $20 \pm 3$ & $11 \pm 5$ & $53 \pm 7$ & 2.91 \\
\hline Cu I 324.75 & $28 \pm 3$ & $25 \pm 4$ & $74 \pm 6$ & 3.81 \\
\hline Ni I 341.476 & $25 \pm 2$ & $14 \pm 5$ & $63 \pm 8$ & 3.65 \\
\hline
\end{tabular}

\section{Crater diameters}
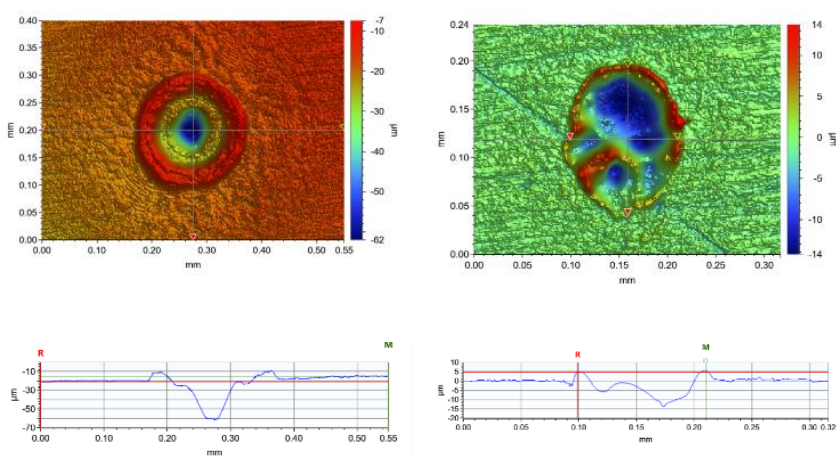

Figure S2 Pictures of ablation craters obtained from 3D optical microscope. Crater on right site is for 3P LIBS with $10 \mathrm{~mJ}$ laser pulse energy and the crater on the left is for SP LIBS with $100 \mathrm{~mJ}$. The optical emission intensity from both laser induced plasmas is comparable. Under each ablation crater is the $\mathrm{X}$ axis profile.

\section{References}

1. D. A. Cremers and L. J. Radziemski, Handbook of Laser-Induced Breakdown Spectroscopy, Wiley, 2 edn., 2013.

2. R. Noll, Laser-induced breakdown spectroscopy, Springer, 2012.

3. D. W. Hahn and N. Omenetto, Appl. Spectrosc., 2010, 64, 335a-366a.
4. D. W. Hahn and N. Omenetto, App/ Spectrosc, 2012, 66, 347419.

5. C. R. Dockery and S. R. Goode, Appl Optics, 2003, 42, 61536158.

6. J. L. Gottfried, F. C. De Lucia, Jr., C. A. Munson and A. W. Miziolek, Anal Bioanal Chem, 2009, 395, 283-300.

7. E. Rodriguez-Celis, I. Gornushkin, U. Heitmann, J. Almirall, B. Smith, J. Winefordner and N. Omenetto, Analytical and bioanalytical chemistry, 2008, 391, 1961-1968.

8. M. T. Taschuk, Y. Y. Tsui and R. Fedosejevs, Appl. Spectrosc., 2006, 60, 1322-1327.

9. A. K. Knight, N. L. Scherbarth, D. A. Cremers and M. J. Ferris, Appl. Spectrosc., 2000, 54, 331-340.

10. D. Prochazka, M. Bilik, P. Prochazkova, M. Brada, J. Klus, P. Porizka, J. Novotny, K. Novotny, B. Ticova, A. Bradac, M. Semela and J. Kaiser, Spectrochimica Acta Part B-Atomic Spectroscopy, 2016, 118, 90-97.

11. L. Radziemski and D. Cremers, Spectrochimica Acta Part B: Atomic Spectroscopy, 2013, 87, 3-10.

12. J. E. Carranza and D. W. Hahn, Spectrochimica Acta Part B: Atomic Spectroscopy, 2002, 57, 779-790.

13. S. I. Gornushkin, I. B. Gornushkin, J. M. Anzano, B. W. Smith and J. D. Winefordner, Appl. Spectrosc., 2002, 56, 433-436.

14. G. Asimellis, S. Hamilton, A. Giannoudakos and M. Kompitsas, Spectrochimica Acta Part B: Atomic Spectroscopy, 2005, 60, 1132-1139.

15. V. N. Rai, J. P. Singh, F. Y. Yueh and R. L. Cook, Laser and Particle Beams, 2003, 21, 65-71.

16. Y. Wang, H. Yuan, Y. Fu and Z. Wang, Spectrochimica Acta Part B: Atomic Spectroscopy, 2016, 126, 44-52.

17. Z. Wang, Z. Y. Hou, S. L. Lui, D. Jiang, J. M. Liu and Z. Li, Opt Express, 2012, 20, A1011-A1018.

18. L. I. Kexue, W. Zhou, Q. Shen, J. Shao and H. Qian, Spectrochimica Acta Part B: Atomic Spectroscopy, 2010, 65, 420-424.

19. Y. Liu, B. Bousquet, M. Baudelet and M. Richardson, Spectrochimica Acta Part B: Atomic Spectroscopy, 2012, 73, 89-92.

20. A. De Giacomo, R. Gaudiuso, C. Koral, M. Dell'Aglio and O. De Pascale, Spectrochimica Acta Part B: Atomic Spectroscopy, 2014, 98, 19-27.

21. L. Sládková, D. Prochazka, P. Pořízka, P. Škarková, M. Remešová, A. Hrdlička, K. Novotný, L. Čelko and J. Kaiser, Spectrochimica Acta Part B: Atomic Spectroscopy, 2017, 127, 48-55.

22. A. Hussain, X. Gao, Z. Hao and J. Lin, Optik - International Journal for Light and Electron Optics, 2016, 127, 10024-10030.

23. V. I. Babushok, F. C. DeLucia, J. L. Gottfried, C. A. Munson and A. W. Miziolek, Spectrochimica Acta Part B: Atomic Spectroscopy, 2006, 61, 999-1014.

24. J. Scaffidi, S. M. Angel and D. A. Cremers, Analytical Chemistry, 2006, 78, 24-32.

25. V. I. Babushok, F. C. Delucia Jr, J. L. Gottfried, C. A. Munson and A. W. Miziolek, Spectrochimica Acta Part B: Atomic Spectroscopy, 2006, 61, 999-1014.

26. E. H. Piepmeier and H. Malmstadt, Analytical Chemistry, 1969, 41, 700-707.

27. R. Scott and A. Strasheim, Spectrochimica Acta Part B: Atomic Spectroscopy, 1970, 25, 311-332.

28. D. A. Cremers, L. J. Radziemski and T. R. Loree, Appl. Spectrosc., 1984, 38, 721-729.

29. J. Uebbing, J. Brust, W. Sdorra, F. Leis and K. Niemax, Appl. Spectrosc., 1991, 45, 1419-1423.

30. D. N. Stratis, K. L. Eland and S. M. Angel, Appl. Spectrosc., 2001, 55, 1297-1303.

31. R. Sattmann, V. Sturm and R. Noll, Journal of Physics D: Applied Physics, 1995, 28, 2181. 
32. A. De Giacomo, M. Dell'Aglio, D. Bruno, R. Gaudiuso and O. De Pascale, Spectrochimica Acta Part B: Atomic Spectroscopy, 2008, 63, 805-816.

33. A. De Giacomo, M. Dell'Aglio, O. De Pascale and M. Capitelli, Spectrochimica Acta Part B: Atomic Spectroscopy, 2007, 62, 721-738.

34. V. Hohreiter and D. W. Hahn, Spectrochimica Acta Part B: Atomic Spectroscopy, 2005, 60, 968-974.

35. P. A. Benedetti, G. Cristoforetti, S. Legnaioli, V. Palleschi, L. Pardini, A. Salvetti and E. Tognoni, Spectrochimica Acta Part B: Atomic Spectroscopy, 2005, 60, 1392-1401.

36. K. Novotný, F. Lutzký, M. Galiová, J. Kaiser, R. Malina, V. Kanický and V. Otruba, 2008.

37. D. N. Stratis, K. L. Eland and S. M. Angel, Appl. Spectrosc., 2000, 54, 1270-1274.

38. A. S. Zakuskin, A. M. Popov, S. M. Zaytsev, N. B. Zorov, M. V. Belkov and T. A. Labutin, J App/ Spectrosct, 2017, 84, 319-323.

39. J. Uebbing, J. Brust, W. Sdorra, F. Leis and K. Niemax, Appl. Spectrosc., 1991, 45, 1419-1423.

40. E. Tognoni and G. Cristoforetti, Journal of Analytical Atomic Spectrometry, 2014, 29, 1318-1338.

41. R. W. Coons, S. S. Harilal, S. M. Hassan and A. Hassanein, Appl Phys B-Lasers O, 2012, 107, 873-880.

42. L. St-Onge, V. Detalle and M. Sabsabi, Spectrochimica Acta Part B: Atomic Spectroscopy, 2002, 57, 121-135.

43. J. Klus, P. Mikysek, D. Prochazka, P. Porizka, P. Prochazkova, J. Novotny, T. Trojek, K. Novotny, M. Slobodnik and J. Kaiser, Spectrochimica Acta Part B-Atomic Spectroscopy, 2016, 123, 143-149.

44. R. Grassi, E. Grifoni, S. Gufoni, S. Legnaioli, G. Lorenzetti, N. Macro, L. Menichetti, S. Pagnotta, F. Poggialini, C. Schiavo and V. Palleschi, Spectrochimica Acta Part B: Atomic Spectroscopy, 2017, 127, 1-6.

45. C. Gautier, P. Fichet, D. Menut, J.-L. Lacour, D. L'Hermite and J. Dubessy, Spectrochimica Acta Part B: Atomic Spectroscopy, 2005, 60, 265-276.

46. G. Galbács, V. Budavári and Z. Geretovszky, Journal of Analytical Atomic Spectrometry, 2005, 20, 974-980.

47. A. Löbe, J. Vrenegor, R. Fleige, V. Sturm and R. Noll, Analytical and Bioanalytical Chemistry, 2006, 385, 326-332.

48. H. Balzer, M. Hoehne, R. Noll and V. Sturm, Analytical and Bioanalytical Chemistry, 2006, 385, 225-233.

49. V. Sturm, J. Vrenegor, R. Noll and M. Hemmerlin, Journal of Analytical Atomic Spectrometry, 2004, 19, 451-456.

50. J. Novotny, M. Brada, M. Petrilak, D. Prochazka, K. Novotny, A. Hrdicka and J. Kaiser, Spectrochimica Acta Part B-Atomic Spectroscopy, 2014, 101, 149-154.

51. P. Yaroshchyk and J. E. Eberhardt, Spectrochimica Acta Part B: Atomic Spectroscopy, 2014, 99, 138-149.

52. R. C. Team, Journal, 2015.

53. E. Voigtman, Spectrochimica Acta Part B: Atomic Spectroscopy, 2008, 63, 154-165. 


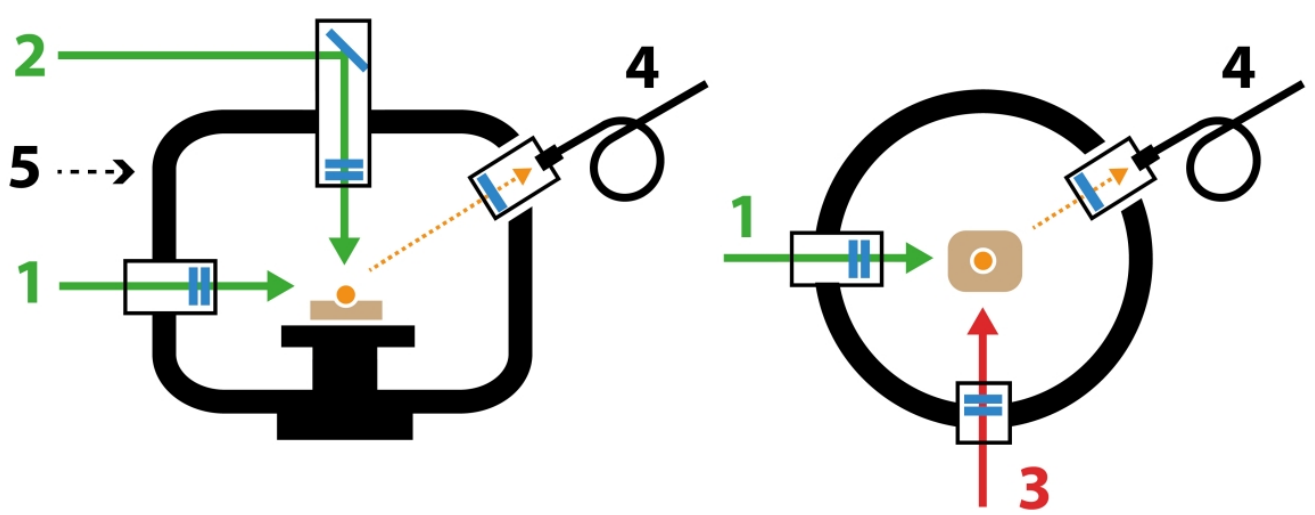

Fig. 1 Front view (left) and top view (right) schematic picture of the interaction chamber with laser pulses and collection optics. All laser pulses are perpendicular to each other. Ablation pulse (2) is directed from the top of the chamber (5), perpendicular to the sample surface, pre-ablation pulse (1) came from the left side of the chamber (5) collinear to the sample surface and re-heating pulse (3) is directed from the front of the chamber (5 )collinear to the sample surface. The collection optics (4) is placed on the right side of the chamber. 


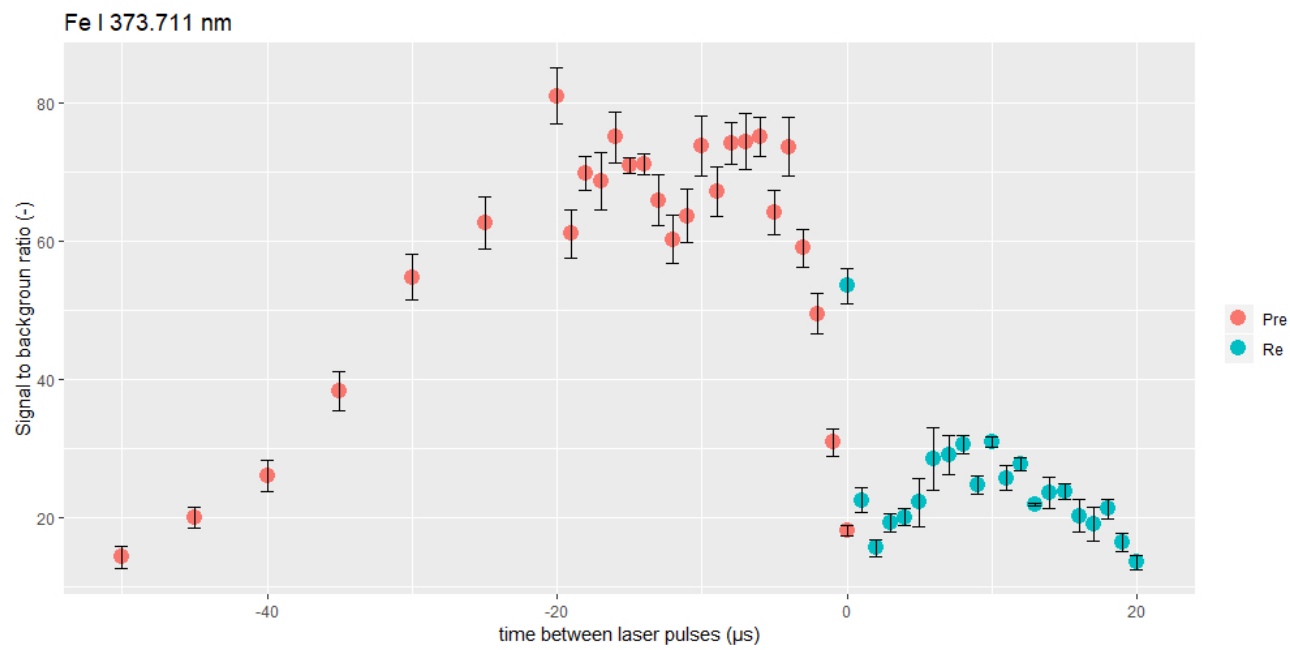

Fig. 2 Signal to background ratio (SBR) as a function of delay between the ablation and pre-ablation and reheating pulse respectively (red points are for pre-ablation and blue points for re-heating). 


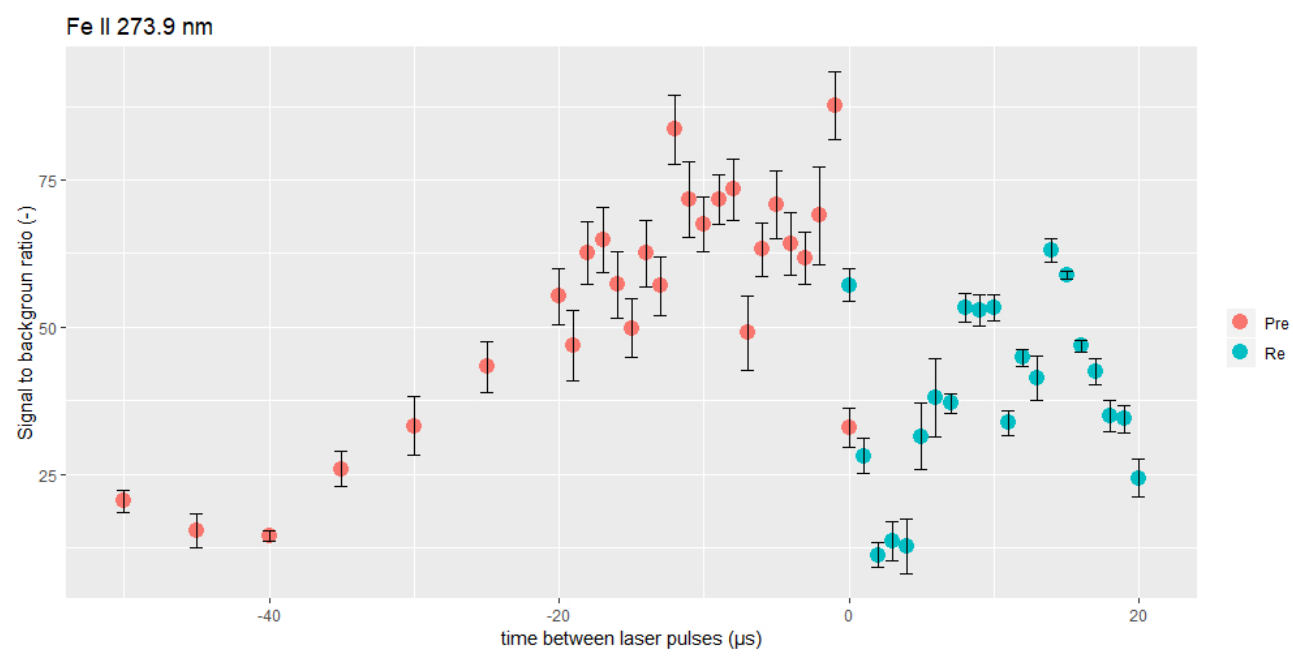

Fig. 2 Signal to background ratio (SBR) as a function of delay between the ablation and pre-ablation and reheating pulse respectively (red points are for pre-ablation and blue points for re-heating). 


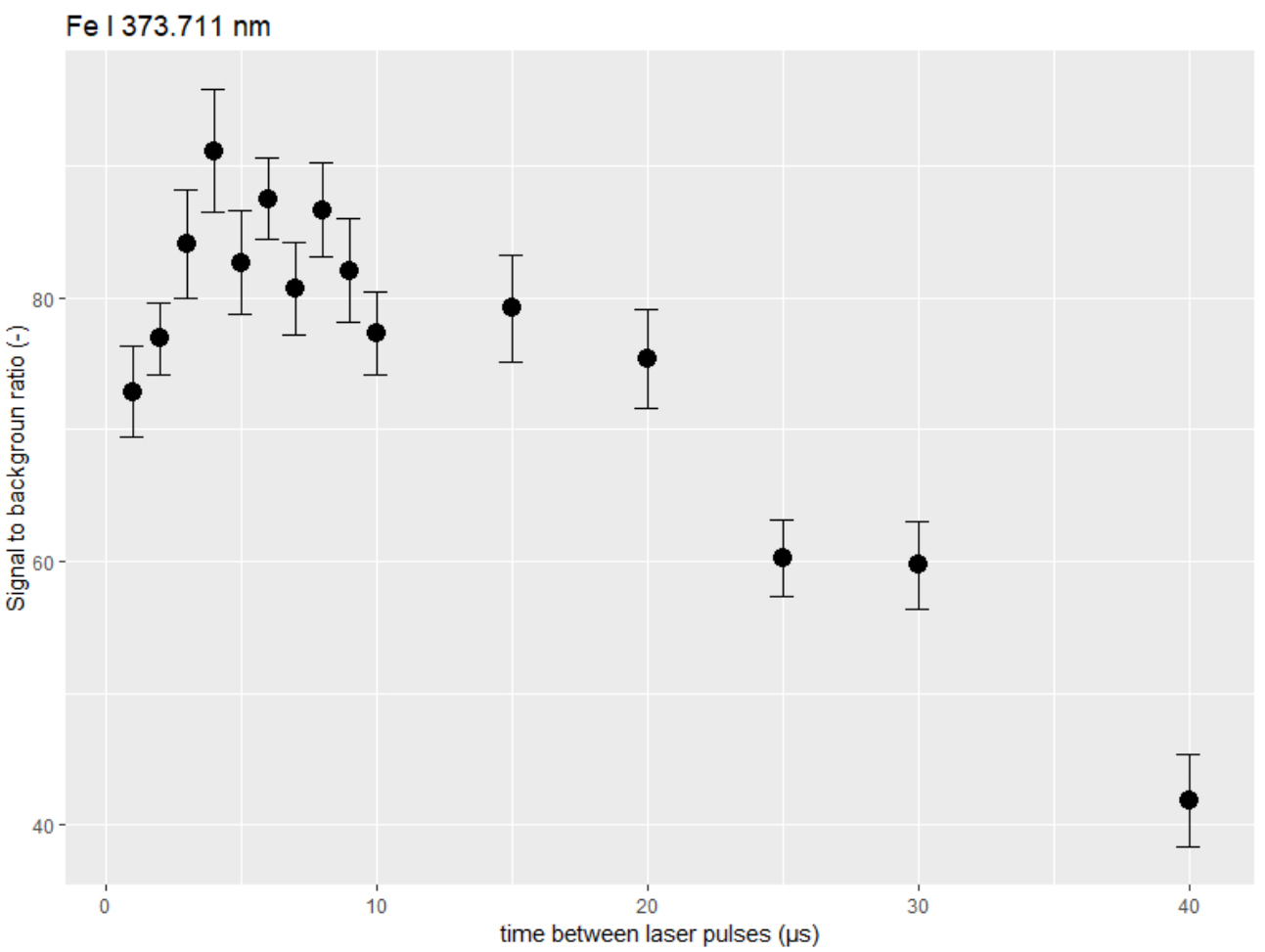

Fig. 3 Signal to background ratio (SBR) as a function of delay after the ablation laser pulse. The pre-ablation pulse was constantly $8 \mu$ s before the ablation pulse. 


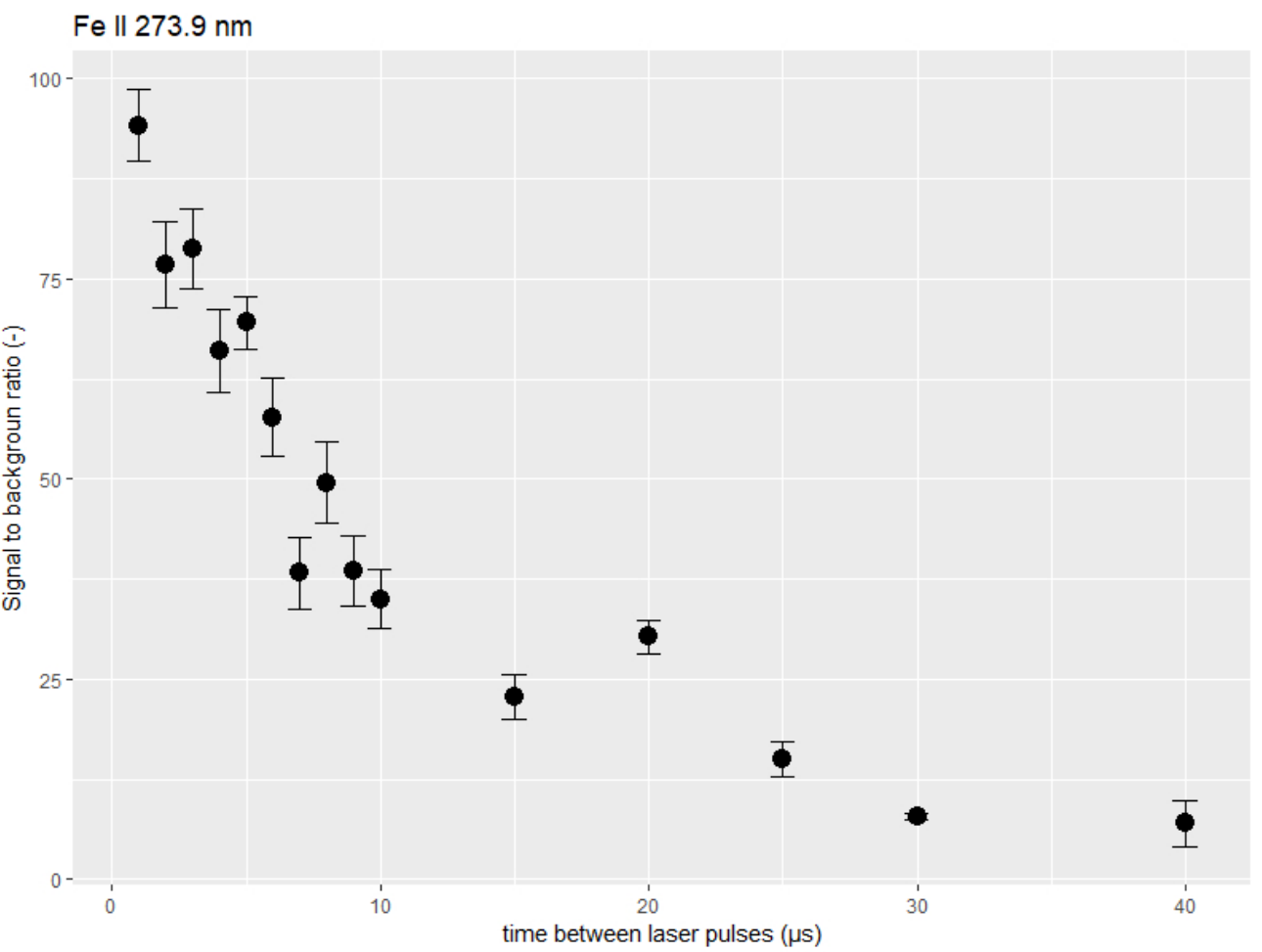

Fig. 3 Signal to background ratio (SBR) as a function of delay after the ablation laser pulse. The pre-ablation pulse was constantly $8 \mu$ s before the ablation pulse. 


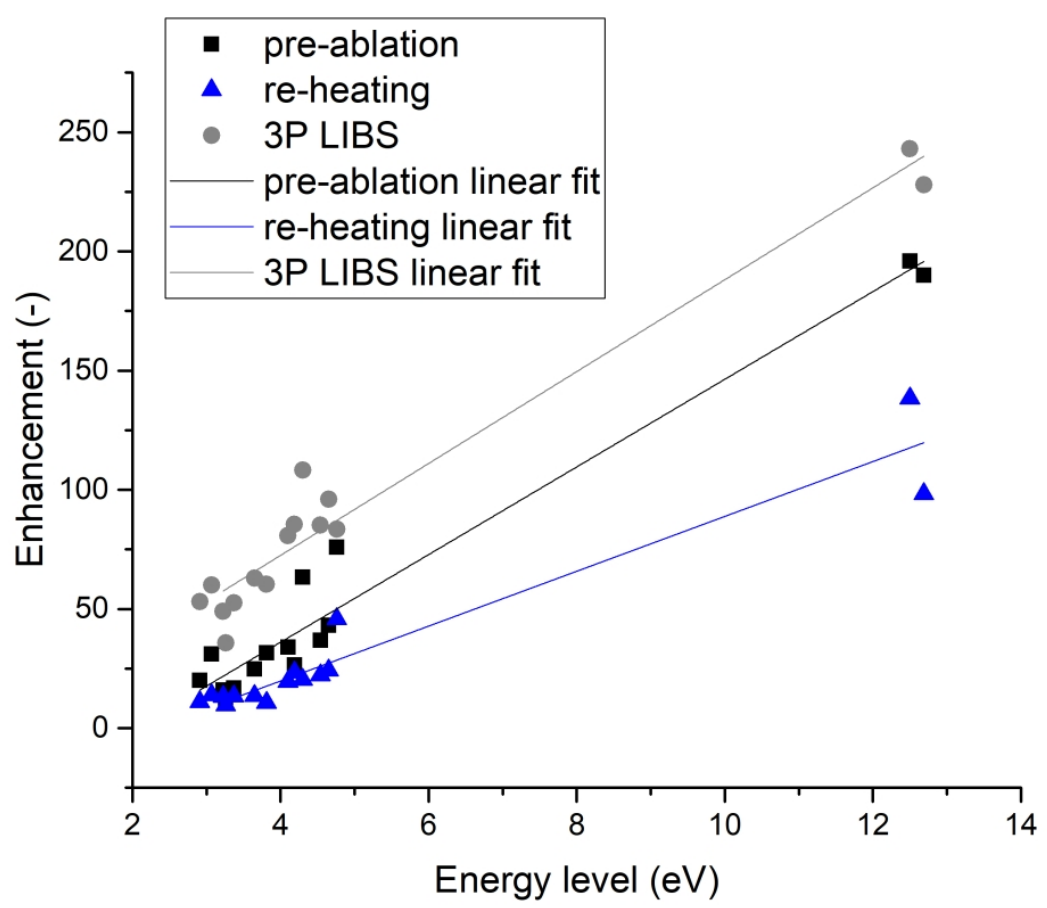

Fig. 5 Enhancement of selected spectral lines as a function of upper-level energy for pre-ablation (squares), re-heating (triangles) and 3P LIBS (circles). The errors are listed in Tab. 2. 


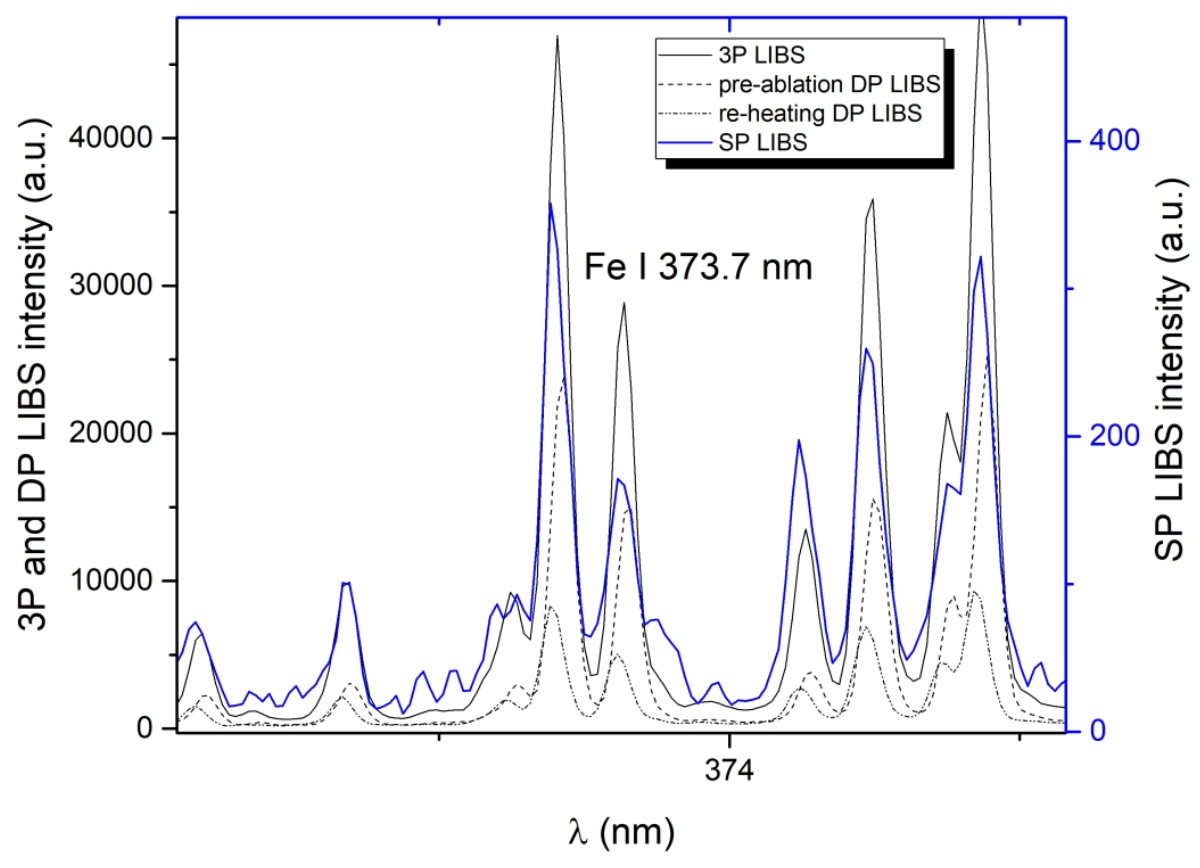




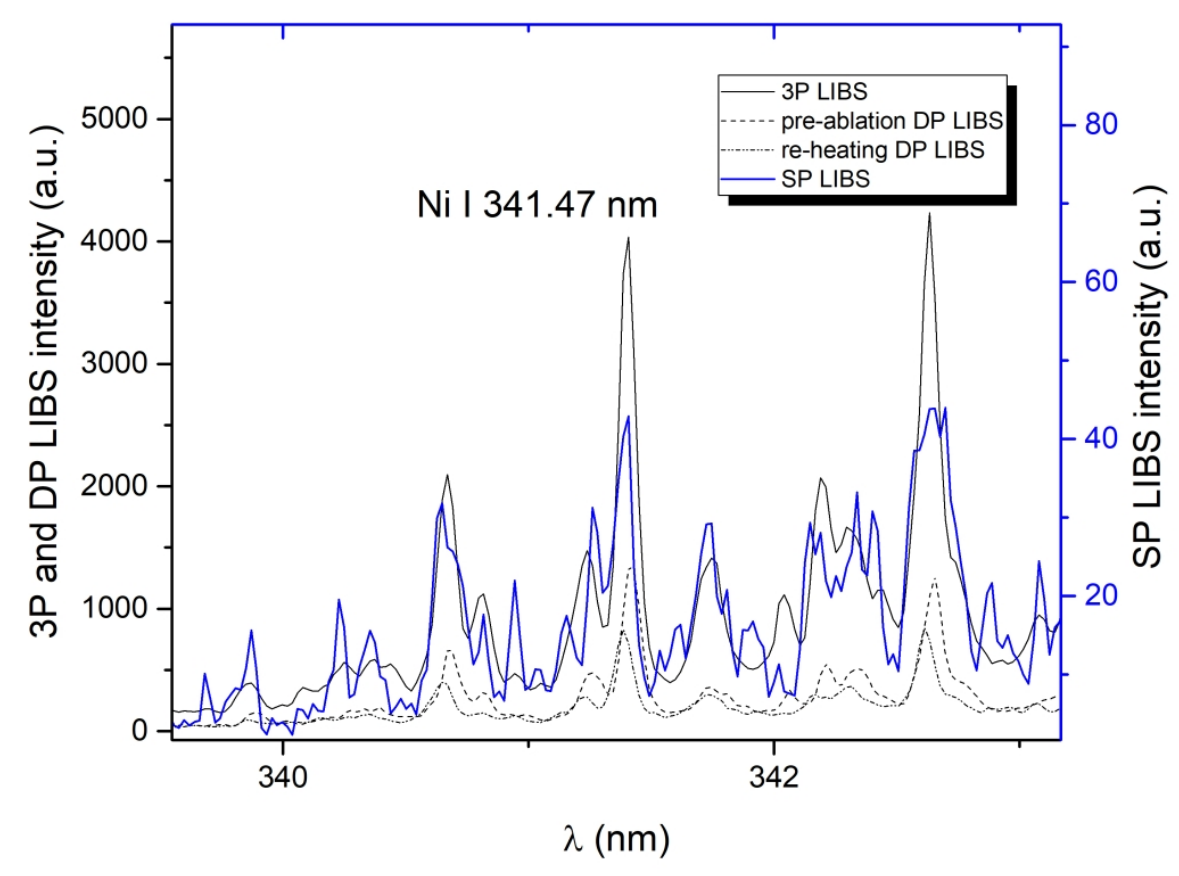




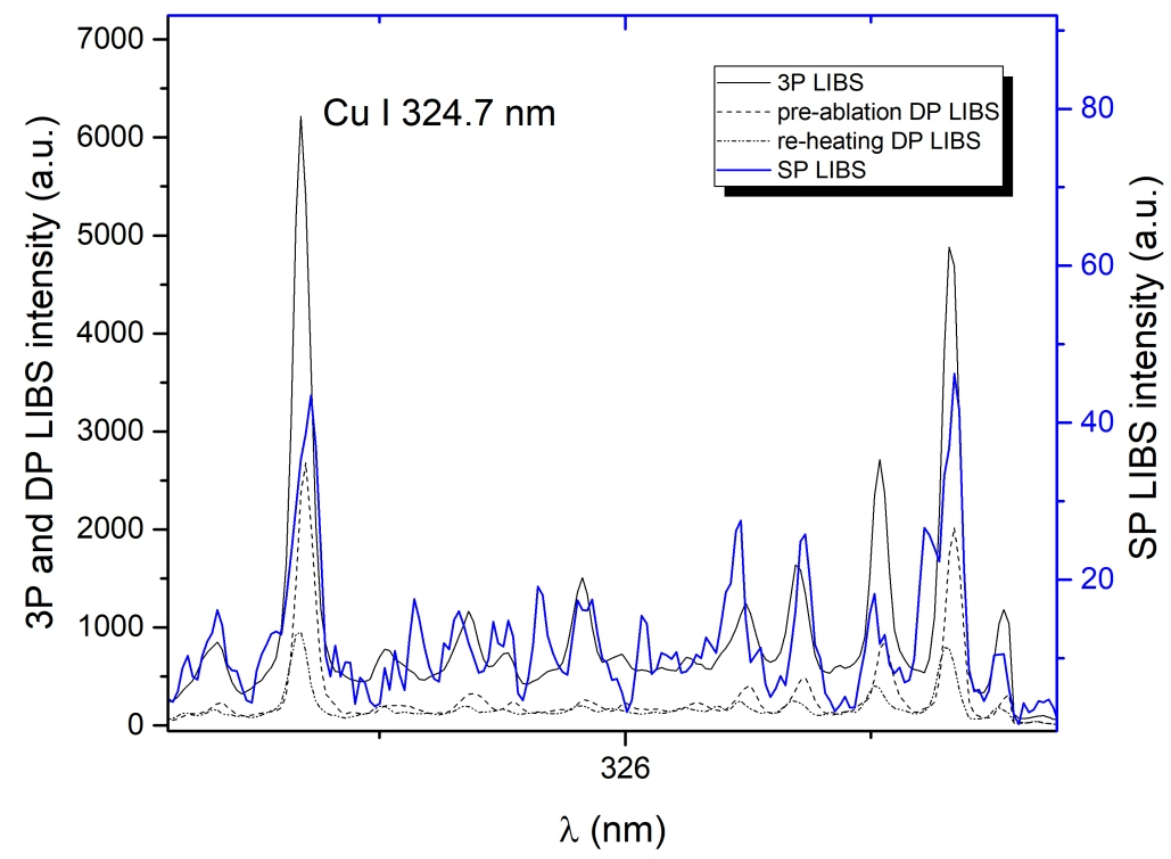




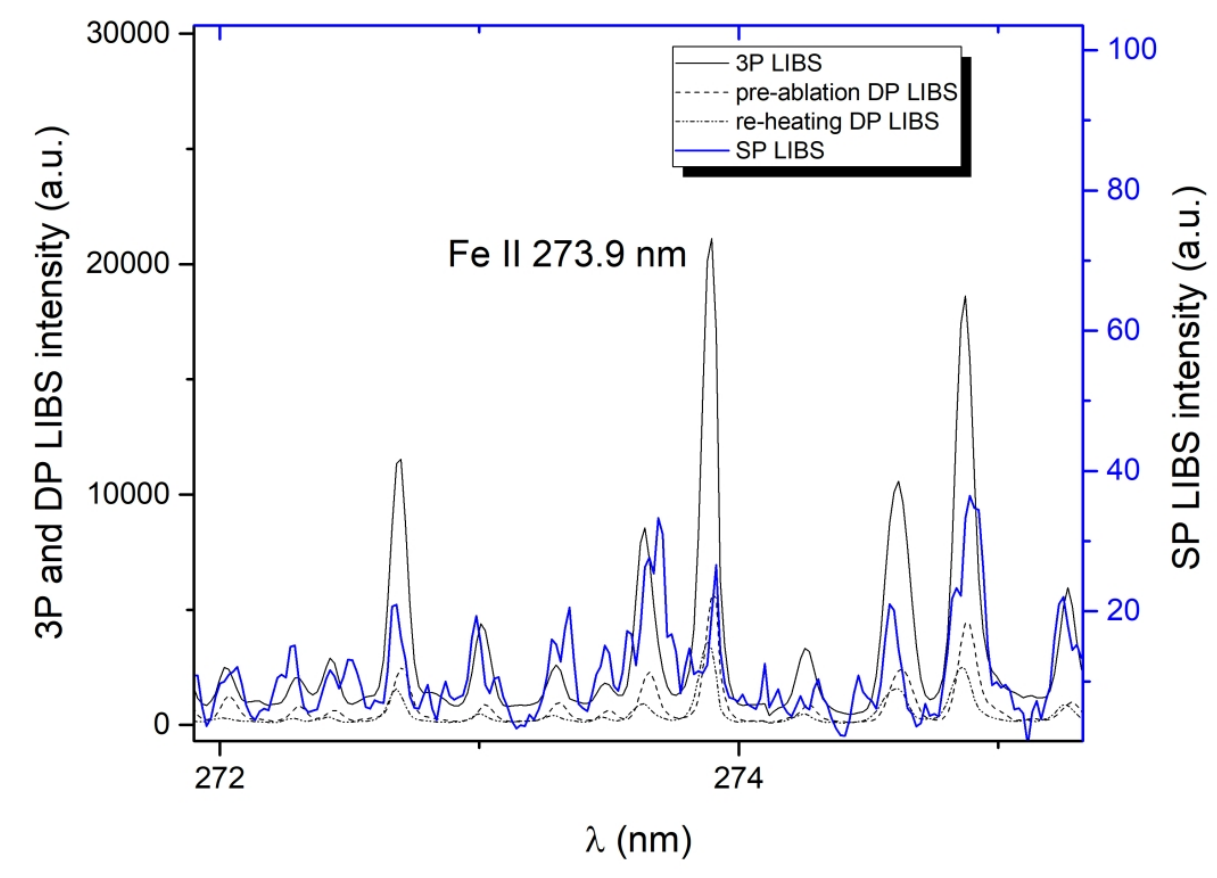




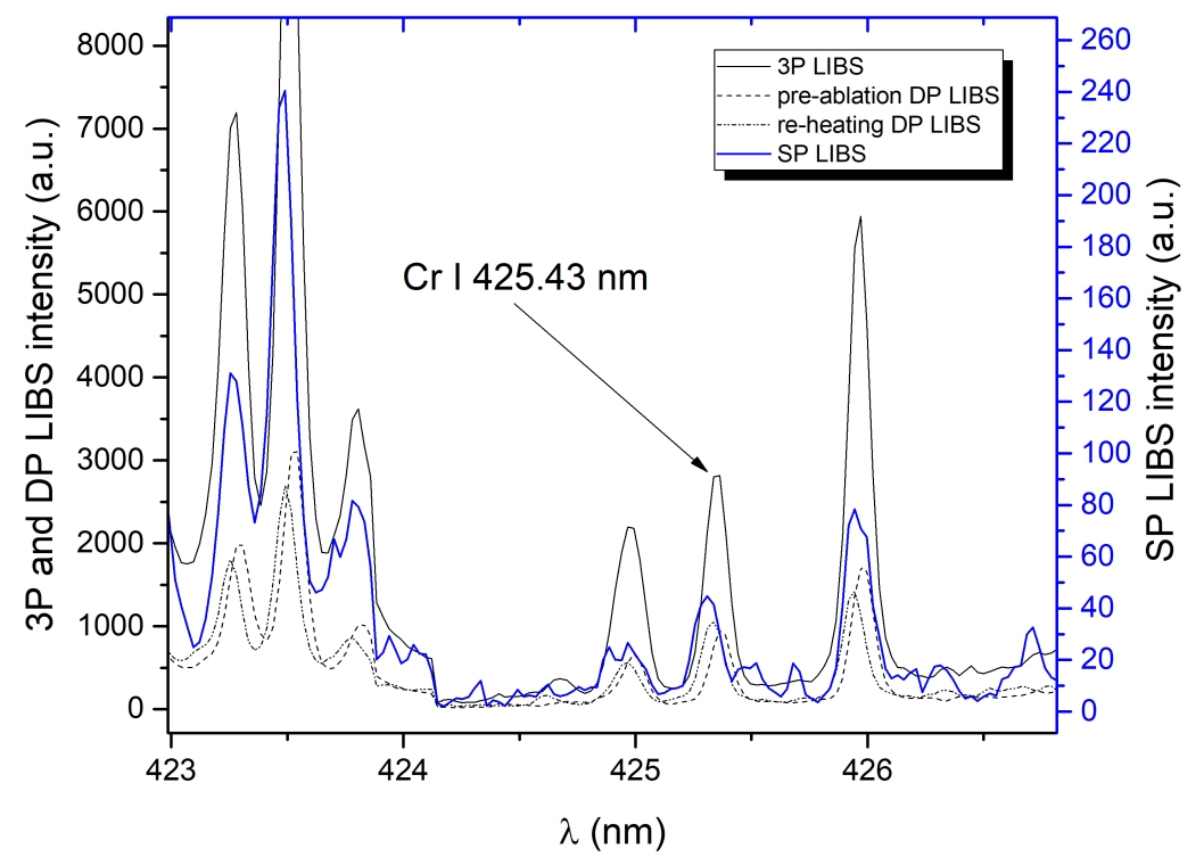




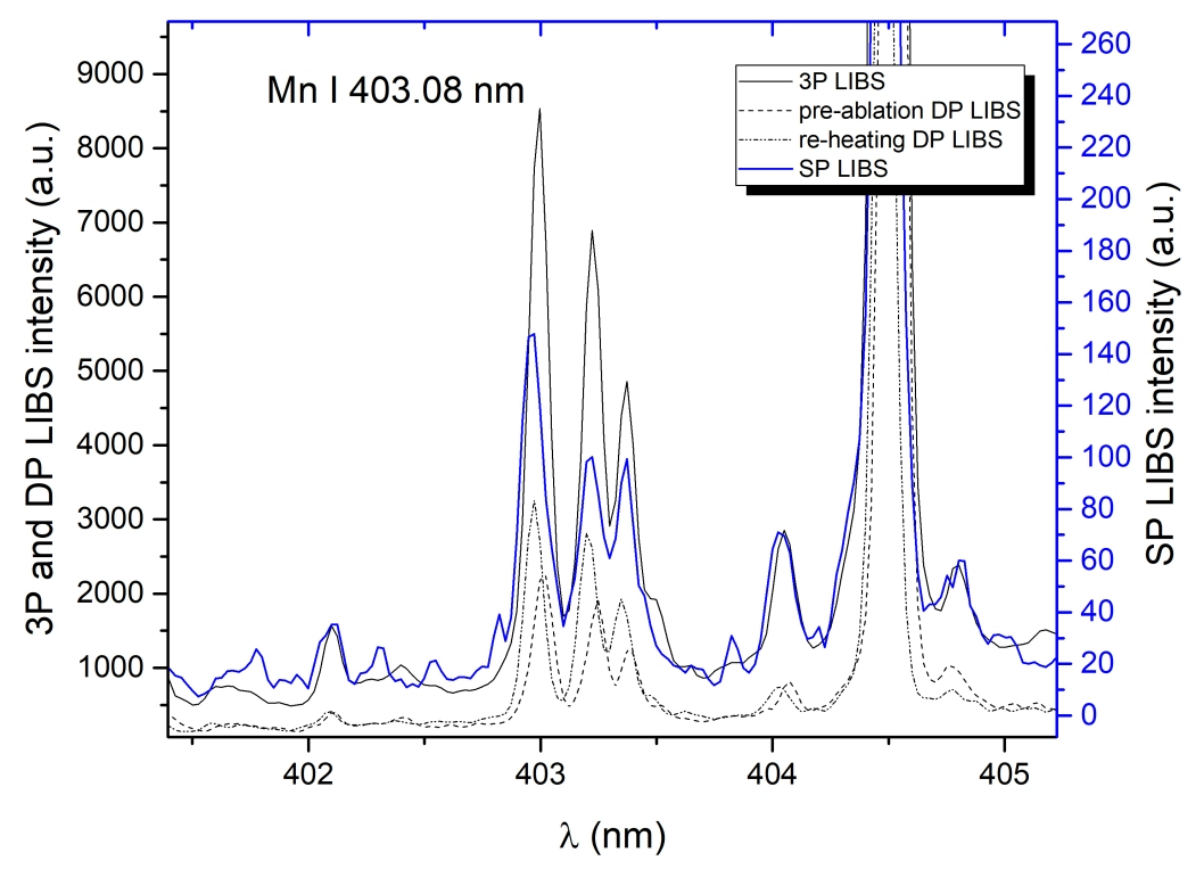




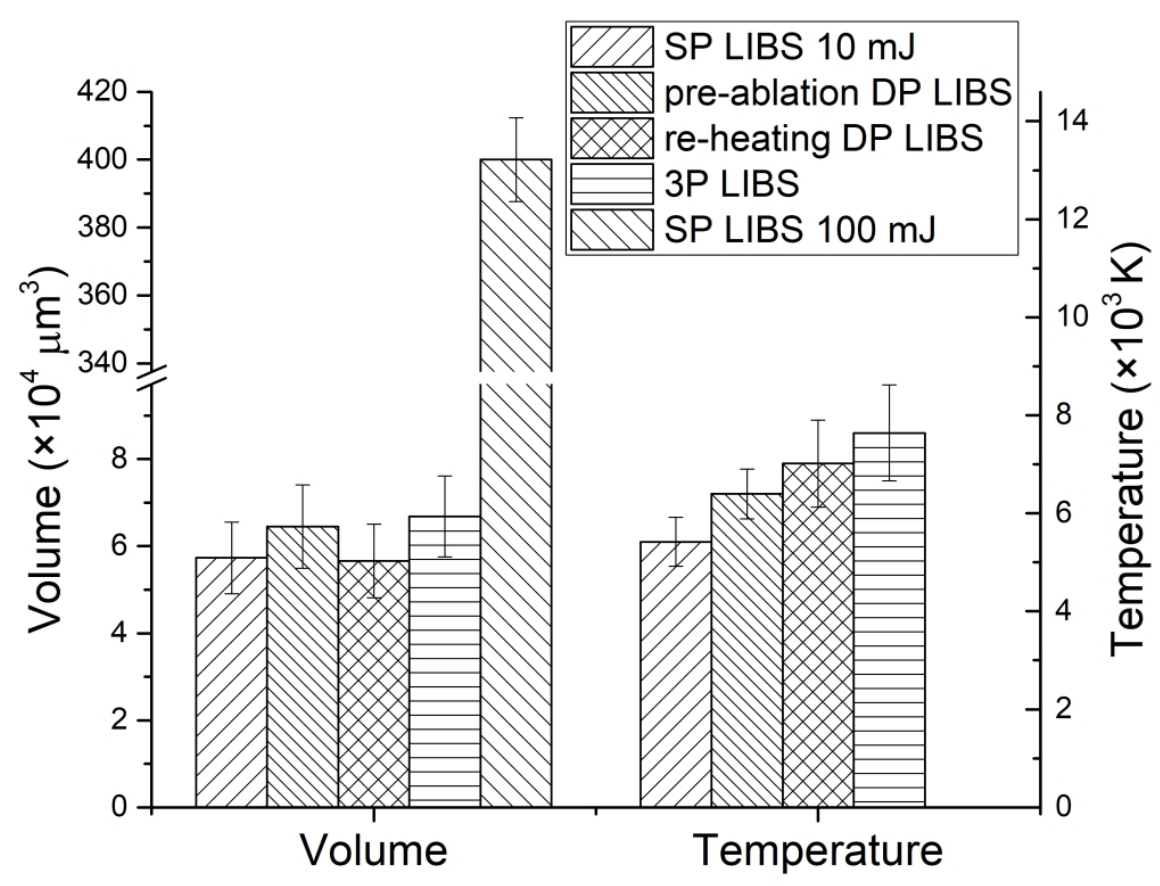




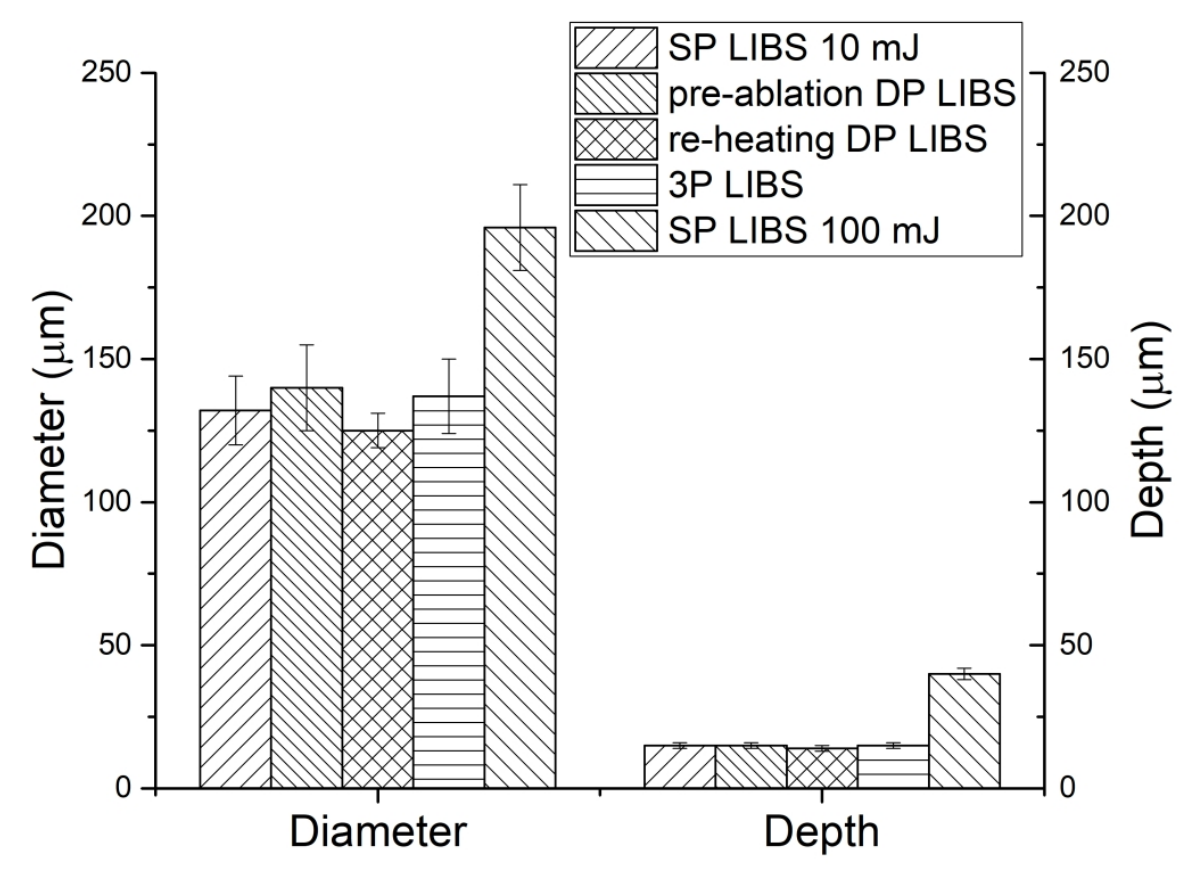




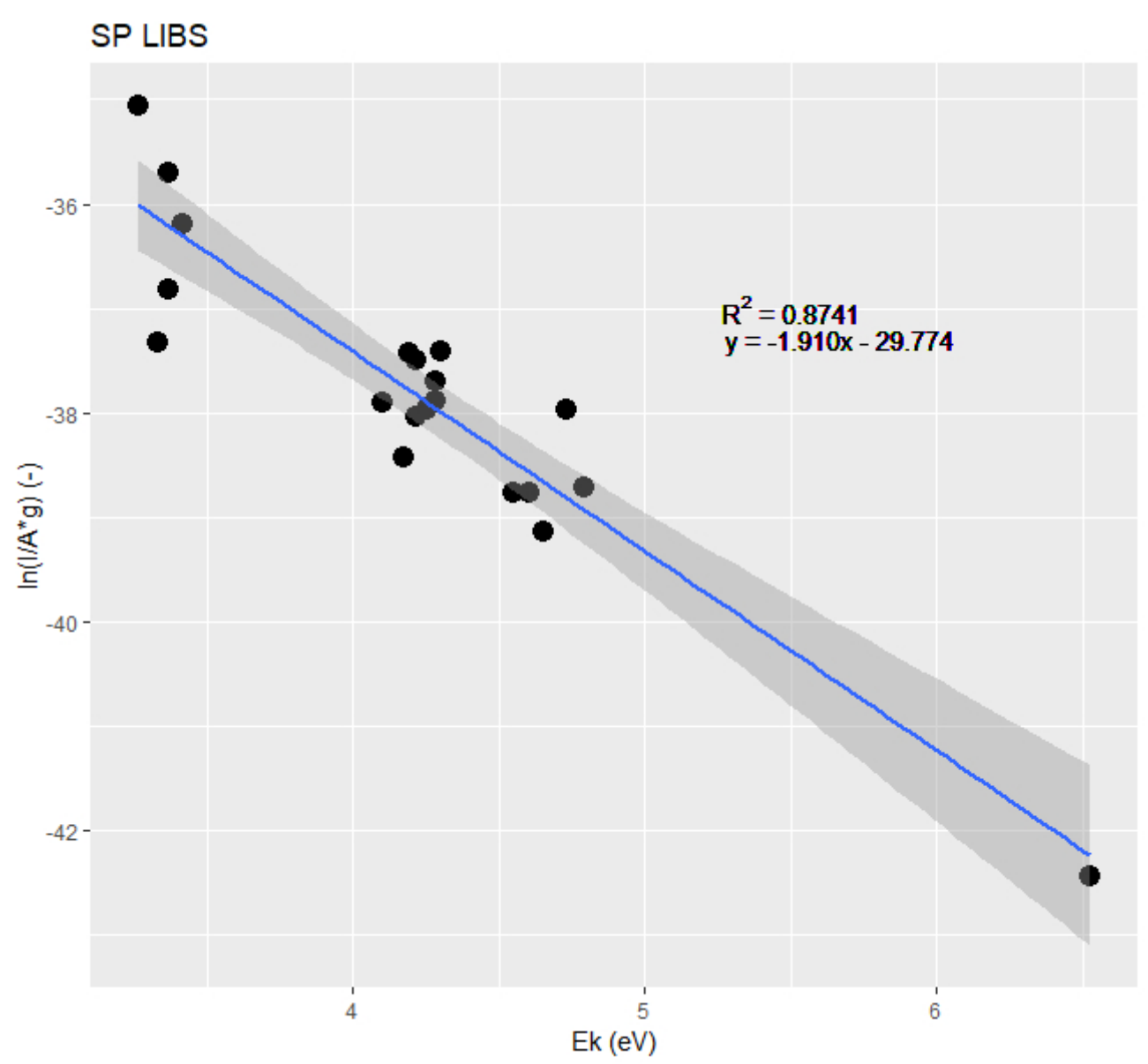




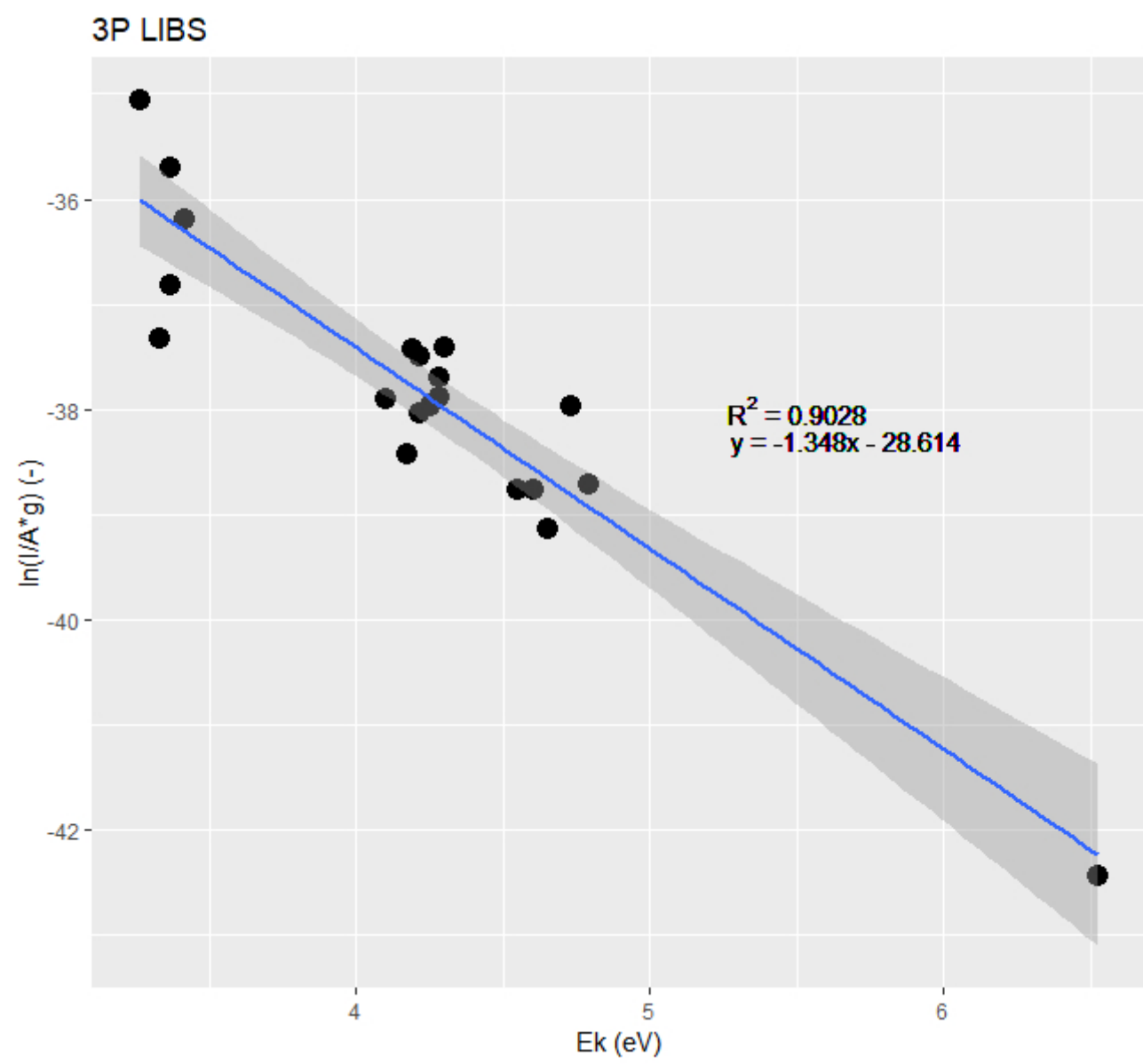




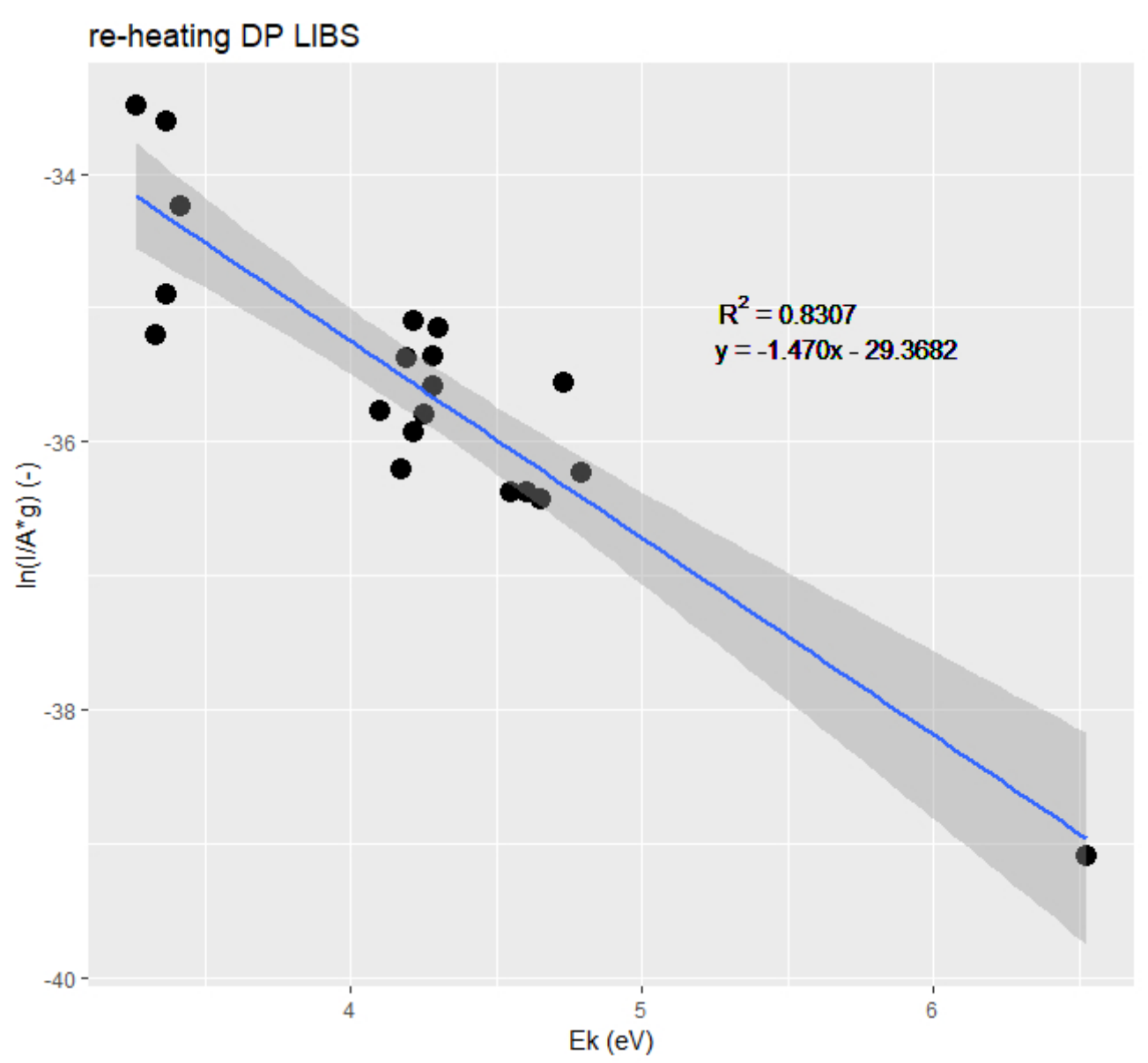




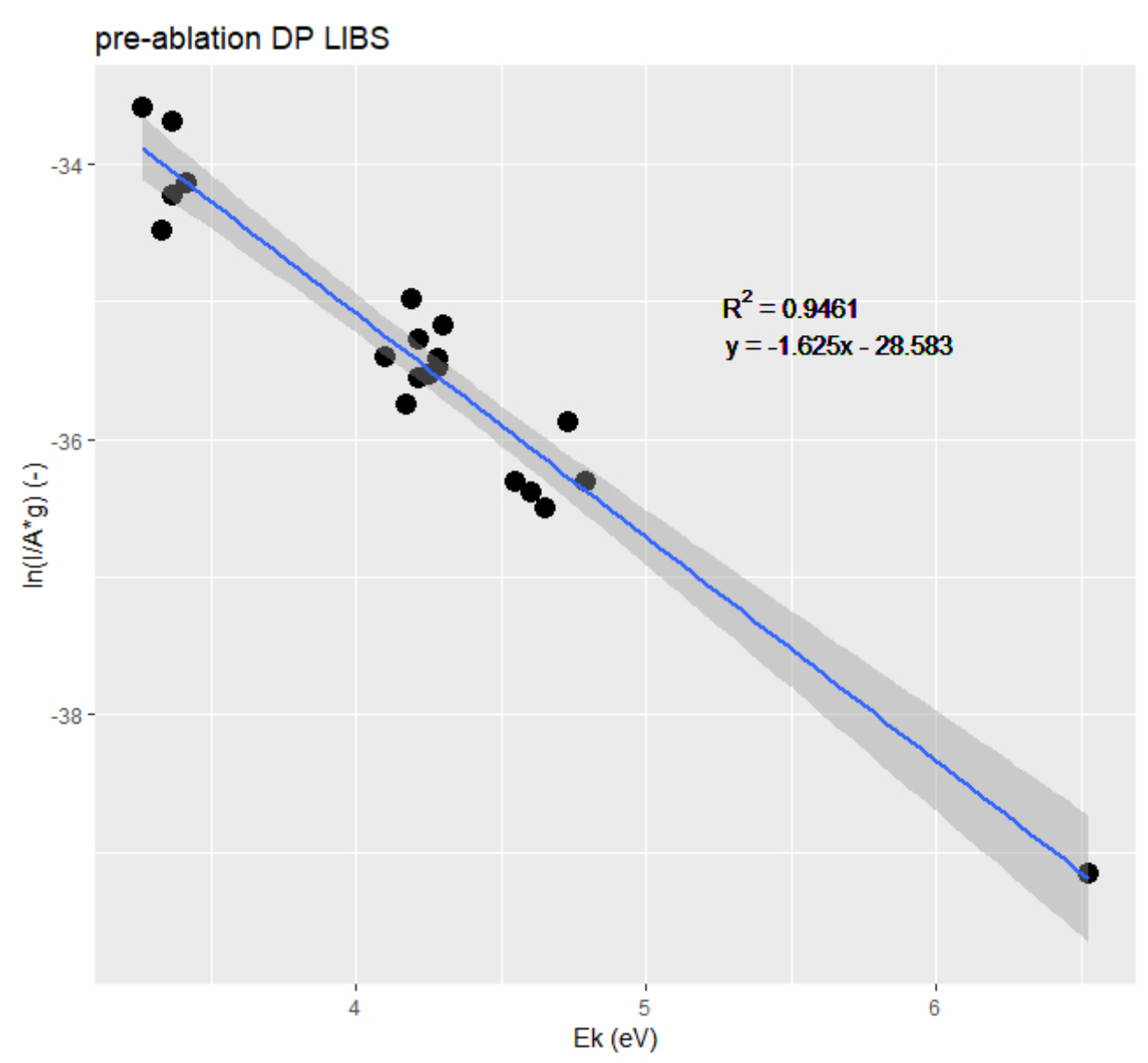

1

2

3

4

5

6

7

8

10

11

12

13

14

15

16

17

18

19

20

21

22

23

24

25

26

27

28

29

30

31

32

33

34

35

36

37

38

39

40

41

42

43

44

45

46

47

48

49

50

51

52

53

54

55

56

57

58

59

60 
1

2

3

4

5

6

7

8

9

10

11

12

13

14

15

16

17

18

19

20

21

22

23

24

25

26

27

28

29

30

31

32

33

34

35

36

37

38

39

40

41

42

43

44

45

46

47

48

49

50

51

52

53

54

55

56

57

58

59

60

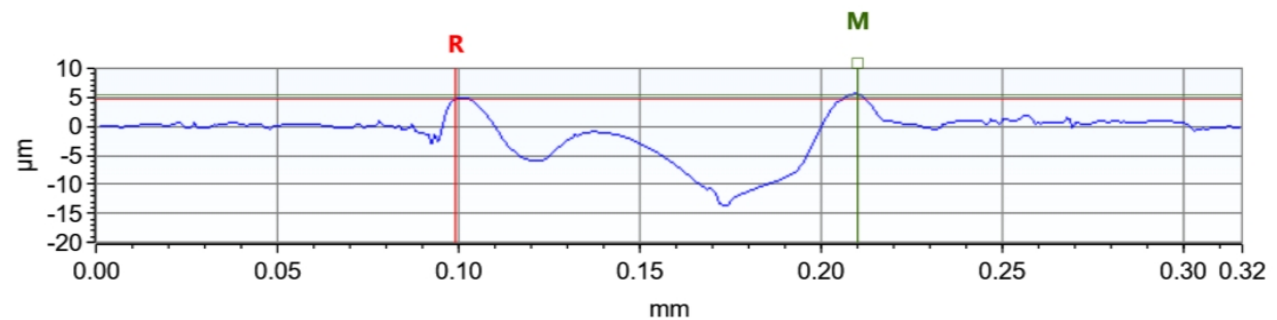


55

56

57

58

59

60

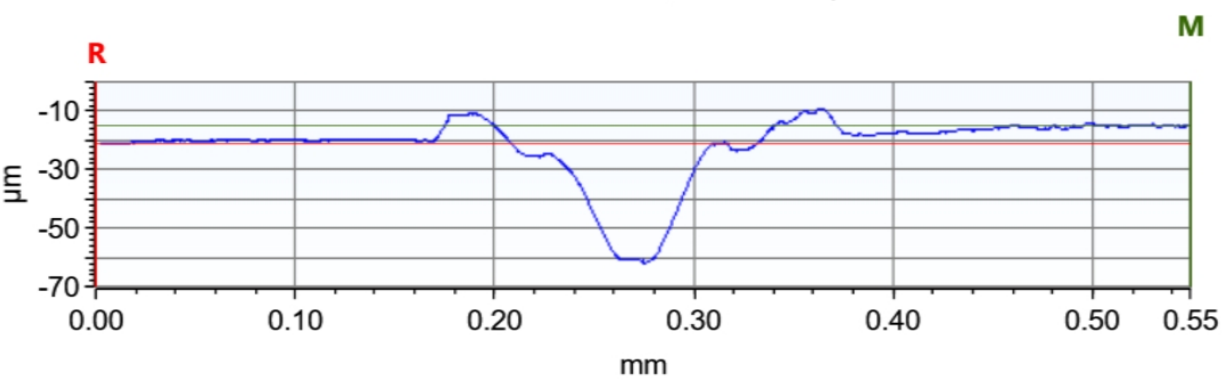




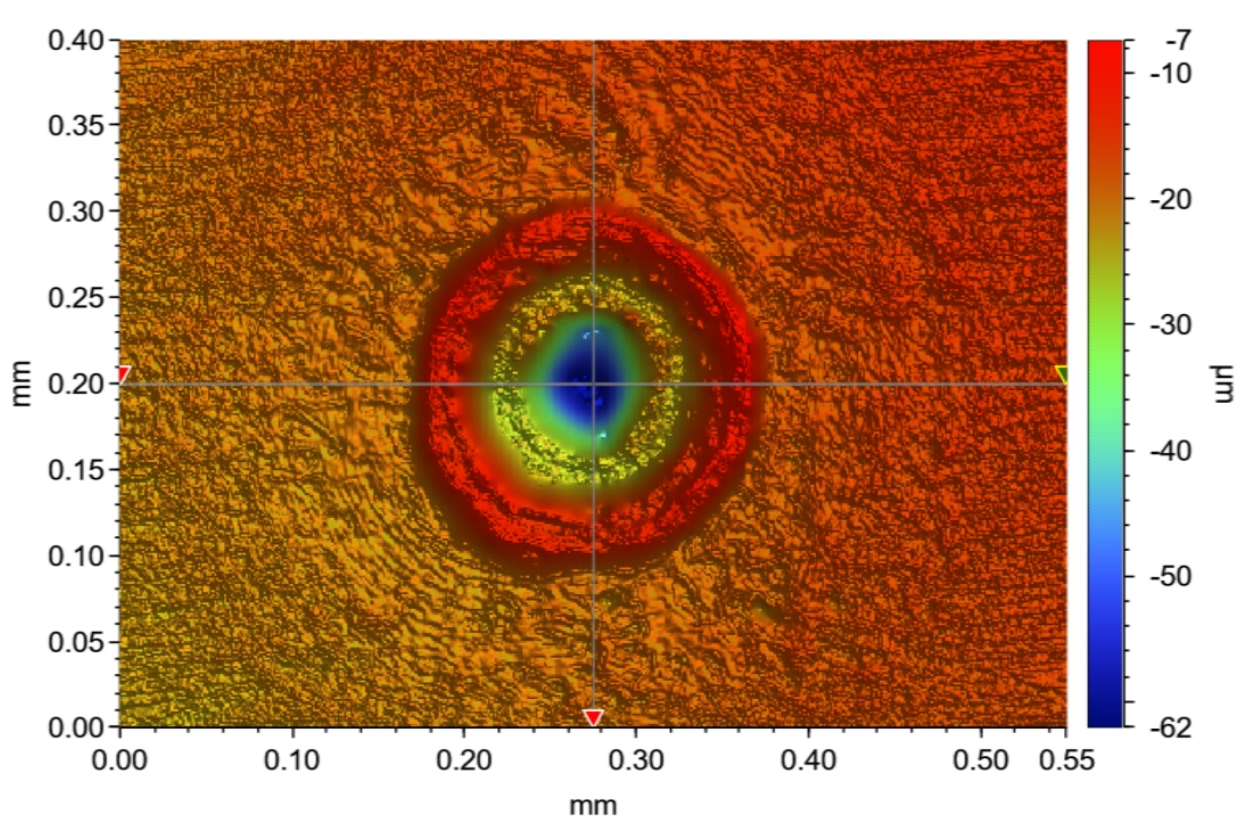




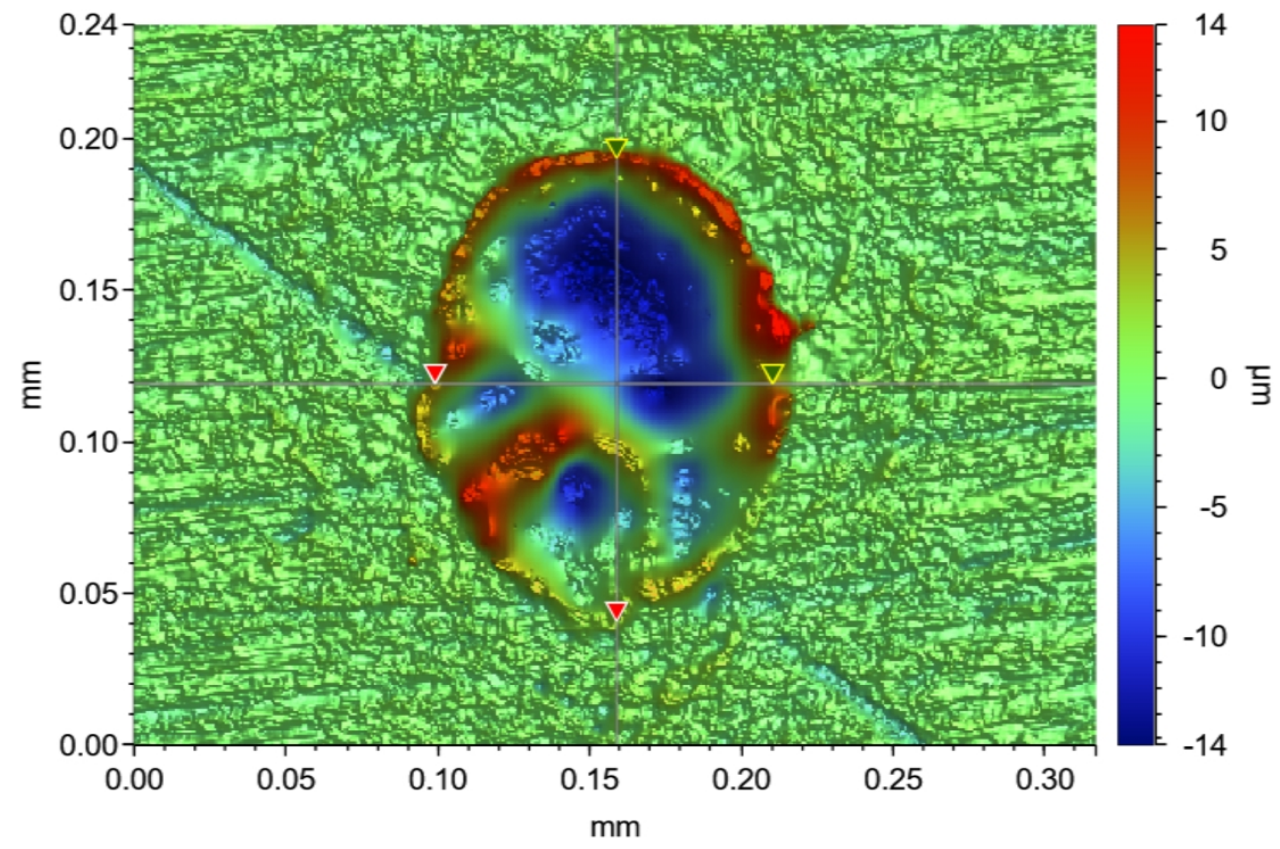

